This PDF is a selection from an out-of-print volume from the National Bureau of Economic Research

Volume Title: International Volatility and Economic Growth: The First Ten Years of The International Seminar on Macroeconomics

Volume Author/Editor: Georges de MÃ@nil and Robert J. Gordon, editors

Volume Publisher: Elsevier Science Publishers B.V., 1991

Volume ISBN: 0-444-89284-2

Volume URL: http://www.nber.org/books/de_m91-2

Conference Date: various

Publication Date: January 1991

Chapter Title: Growth and External Debt Under Risk of Debt Repudiation

Chapter Author: Daniel Cohen, Jeffrey Sachs

Chapter URL: http://www.nber.org/chapters/c11689

Chapter pages in book: (p. 437 - 472) 


\title{
GROWTH AND EXTERNAL DEBT UNDER RISK OF DEBT REPUDIATION*
}

\author{
Daniel COHEN \\ CEPREMAP, Paris, France \\ Jeffrey SACHS \\ Harvard University and National Bureau of Economic Research, \\ Cambridge, MA 02138, USA
}

\begin{abstract}
We analyze the pattern of growth of a nation which borrows abroad and which has the option of repudiating its foreign debt. We show that the equilibrium strategy of competitive lenders is to make the growth of the foreign debt contingent on the growth of the borrowing country. We give a closed-form solution to a linear version of our model. The economy, in that case, follows a two-stage pattern of growth. During the first stage, the debt grows more rapidly than the economy. During the second stage, both the debt and the economy grow at the same rate, and more slowly than in the first stage. During this second stage, the total interest falling due on the debt is never entirely repaid; only an amount proportional to the difference of the rate of interest and the rate of growth of the economy is repaid each period.
\end{abstract}

\section{Introduction}

When borrowers have an option to repudiate their debts, the interactions of borrowers and lenders over time presents a strategic situation of enormous complexity. Consider the case of a sovereign borrowing country, raising loans from the world capital market. Following Eaton and Gersovitz (1981), suppose that repudiation of the debt results in financial autarky and a loss of productive efficiency of the defaulting country. An indebted country must balance these costs with the direct costs of debt repayment, in considering the option of repudiation. In turn, credit rationing will emerge from the lenders' decision to limit their exposure to a level low enough to render debt repudiation an inferior option to the borrowing country.

It turns out that the lenders' strategy is not easy to compute. The simple maxim is to lend freely to the point where the country is indifferent between

\footnotetext{
*Paper presented at the International Seminar on Macroeconomics, Chateau de Ragny, France, June 1985. The authors would like to thank Atish Ghosh, who designed and implemented the numerical dynamic programming algorithm used in section 4 of the paper.
} 
debt repayment and repudiation. But what point is that? One of the incentives for debt repayment is the option to borrow again in the future. But the value of that option depends on how much lenders will lend in the future. That in turn will depend on the future lenders' assessment of the point of indifference of the country between repayment and repudiation, which in turn will depend on the capacity of the country to borrow in the still further distant future. Thus we have a problem of infinite regress, and the method of dynamic programming is needed to solve the lenders' problem.

In this paper, we examine a growth model in which sufficiently many linearities allow us to give a closed form solution to the lender's and borrower's strategies. We also describe an algorithm and a suitable numerical technique to solve for borrower and lender behavior in more complex, nonlinear settings. In the analytical version of the model, the borrowing country goes through two borrowing stages: (1) a stage with unconstrained borrowing and a rising external-debt-to-GDP ratio, with the rate of GDP growth falling progressively; and (2) a stage with a constant, low rate of GDP growth and constrained (rationed) borrowing. During the second stage (which always occurs after a finite time), the country never repays the full amount of interest falling due but only the fraction which is necessary to make the debt grow at the same rate as the GDP of the country.

Section 2 sets out the model. Section 3 analyzes the optimal lending strategy when default is an available alternative to the borrower, and presents analytical results in the linear version of the model. Section 4 briefly discusses the use of numerical techniques for more general models. Finally, section 5 examines the sensitivity of the equilibrium to alternative lending strategies. A conclusion summarizes the paper. All technical derivations are presented in four appendices.

\section{The model}

We study a discrete-time growth model of a small country which has access to an international capital market. We assume that the consumption, investment and borrowing decisions are made by a social planner maximizing an intertemporal utility function. The numeraire (both national and international) is a good which serves for both consumption and investment. The international rate of interest is assumed to be a constant, $r$. In this paper we do not deal with the important distinction between traded and nontraded goods. This will enable us to use $G D P$ as a measure of the potential foreign-exchange revenues of the country. In a more general framework, one should be careful to use the production of traded goods as the measure of the revenues which enable the country to repay its debt [see Cooper and Sachs (1984) and Dornbusch (1983)]. 


\subsection{Technology and capital installation}

The technology available to the country is described by a linear production function with only one input, capital,

$$
Q_{t}=a K_{t}
$$

$Q_{t}$ is $G D P$ at time $t$, and $K_{t}$ installed capital. (In section 4 , we briefly examine the case of more general technologies.) Installed capital depreciates at rate $d$, so that the net increment to installed capital is

$$
K_{t+1}=I_{t}+(1-d) K_{t}
$$

where $I_{t}$ is the flow of newly installed capital. If there were no installation costs; a social planner able to borrow at a world interest rate $r$ would choose either to invest or disinvest at an infinite rate depending on whether $r$ is less than or greater than $a-d$. In what follows, we shall assume the inequality

$$
r<a-d,
$$

so that the planner would choose to invest at an infinite rate. In fact, we shall also assume that installation of capital is costly. Following Abel and Hayashi, we let $J_{t}$, total investment expenditure, and $I_{t}$, the flow of new installed capital, be related by the functional form

$$
J_{t}=\left[1+(1 / 2) \phi\left(I_{t} / K_{t}\right)\right] I_{t} .
$$

The unit cost to install capital is therefore $(1 / 2) \phi\left(I_{t} / K_{t}\right)$, which increases with the rate of capital accumulation. With this formulation, the planner will always choose to invest at a finite rate.

\subsection{The wealth of the country}

We shall define the productive wealth $W$ of the country as the discounted value of current and future production net of the investment expenditure, using the world interest rate as the discount factor

$$
W_{t}=\sum_{i=t}^{\infty}(1+r)^{-(i-t)}\left(a K_{i}-J_{i}\right)
$$

It is easy to show [see Appendix 2, eqs. (A2.5) to (A2.10)] that the wealth so defined is maximized by selecting a fixed rate of capital accumulation

$$
x^{*}=I_{t} / K_{\imath}
$$


Capital stock growth is then given by

$$
K_{t+1} / K_{t}-1=g^{*} \equiv x^{*}-\dot{d}
$$

From now on, we shall assume that the value of $g^{*}$ satisfies $g^{*}<r$ so that the infinite sum in (5) is meaningful. We show in Appendix 2 (A2.9) that the value $x^{*}$ maximizing $W_{t}$ and satisfying (3) is

$$
x^{*}=(r+d)[1-\sqrt{1-(2 / \phi)(a-d-r) /(r+d)}]
$$

This value of $x^{*}$ exists under the condition

$$
\phi>2(a-d-r) /(r+d) .
$$

(9) says that installation cost must be sufficiently large so as to make the maximum rate of capital accumulation lower than the rate of interest. We henceforth assume that (9) holds.

\subsection{Optimizing behavior of the country}

We shall assume that the country is governed by a social planner maximizing a time-separable utility function of the form

$$
U=\sum_{t=0}^{\infty} \beta^{t} \log C_{t}
$$

The choice of logarithmic utility helps to preserve key linearities necessary for a closed-form solution.

When the constraint on foreign borrowing is not binding, the optimal consumption path will satisfy

$$
C_{t+1} / C_{t}=\beta(1+r)
$$

From now on we shall assume

$$
\beta(1+r)<1+g^{*}
$$

which guarantees that the planner discounts the future sufficiently to desire to be a net borrower.

\subsection{Foreign borrowing}

The international capital market is assumed to be competitive, and to supply loans at a fixed interest rate $r$ (though in a rationed quantity, yet to 
be determined). All loans are for one period, with $D_{t}$ denoting the principal repayments due at time $t$, and $r D_{t}$ the interest payments due at time $t$. The balance of payments equation is

$$
D_{t+1}=(1+r) D_{t}+C_{t}+I_{t}\left[1+(\phi / 2)\left(I_{t} / K_{t}\right)\right]-Q_{t} .
$$

In general, as described in section 3 , new borrowing will be limited by a constraint of the form $D_{t+1} \leqq h\left(K_{t+1}\right)$. The goal is to characterize the $h\left(K_{t+1}\right)$ function, and to study optimal borrowing under that constraint.

\subsection{The threat of repudiation}

We shall assume that the planner has the option of repudiating the country's external debt. If it does so, it suffers two penalties. First, the country permanently loses its access to international capital markets so that it is forced into financial autarky. Second, there is a direct penalty on production following debt repudiation (due, for example, to a loss of efficiency following increased difficulties in foreign trade) so that the productivity of capital becomes $a(1-\lambda)$ for some $\lambda \in[0,1]$. GDP hence becomes

$$
Q_{t}=a(1-\lambda) K_{t} .
$$

Given these constraints, a defaulting country can reach an autarkic intertemporal utility level, which we name $V^{\mathrm{D}}\left(K_{t}\right)$. Note that this utility level is a function of the stock of capital in place when the decision to default is taken. We show in Appendix 1, eq. (A1.8), that $V^{\mathrm{D}}\left(K_{\imath}\right)$ is of the form

$$
V^{\mathrm{D}}\left(K_{t}\right)=\log \left(K_{t}\right) /(1-\beta)+\text { constant }
$$

The constant term is a decreasing function of $\lambda$. We shall assume full information of both creditors and debtors of the value of $\lambda$, as well as of the level of the capital stock. Given this absence of uncertainty, default will never happen: the lenders will select a supply of credit such that the borrower will never find it profitable to repudiate its debt. The main purpose of section 3 will be to find this loan supply and to derive its consequences for the growth of the country.

\section{Equilibrium with repudiation}

We now examine the consequences of a threat of debt repudiation on the strategies available to the lenders, and on the rate of growth of the borrowing economy. At each point of time, the country has built up both external debt and productive capital. In order to decide whether to default or 
to repay the debt coming due, the country has to compare the autarkic utility level $V^{\mathrm{D}}(K)$, which is a function of installed capital only, with the utility it can derive by servicing the debt and at least postponing the decision to default. The subtlety of the problem is that the country's decision depends in part on the future credit lines it expects from the lenders, who must relate their lending decisions to the country's present and future choices. Technically, the solution must be obtained by backward recursion. Given the constraints on lending that the country is expected to face in the future, present lenders must keep their exposure to a level which keeps the country from defaulting on its current debt.

Solving the problem in its full generality is a hard task and simplifications are needed to find a closed form solution. An example is solved in Eaton and Gersowitz by assuming a fixed cyclical pattern to the country's output, and no capital accumulation. In our previous work $(1984,1985)$, a three-period horizon allowed us to solve a model with uncertainty via backward recursion. In the model here, the many linearities which we imposed on consumer tastes and on production technology enable us to give a closedform solution to the problem in an infinite-horizon model with capital accumulation. Before we solve our specific model, we first set the problem in its general form.

\subsection{Finitely-lived economy}

In order to show how backward recursion is used to find the optimal decision rule of the lenders, we first assume that the horizon of the country ends at some finite time $T$.

Let us assume that the country has not defaulted before the last period and that it has accumulated by then a capital stock $K_{T}$ and an external debt $D_{T}$ (with debt $D_{T}$, the country owes $(1+r) D_{t}$ in the last period). During the last period, the decision to repay or to default is straightforward since the country has only to compare the costs and benefits of defaulting in one period. We define [following Eaton and Gersovitz (1981)]

$$
\begin{aligned}
& V_{T}\left(K_{T}, D_{T}\right)=\max \left\{V_{T}^{\mathrm{R}}\left(K_{T}, D_{T}\right), V_{T}^{\mathrm{D}}\left(K_{T}\right)\right\}, \text { with } \\
& V_{T}^{\mathrm{R}}\left(K_{T}, D_{T}\right)=\log \left[a K_{T}-(1+r) D_{T}\right], \quad \text { and } \\
& V_{T}^{\mathrm{D}}\left(K_{T}, D_{T}\right)=\log \left[(1-\lambda) a K_{T}\right],
\end{aligned}
$$

where $V_{T}^{\mathrm{R}}$ denotes the utility that the country can reach by repaying its debt at time $T$, and $V_{T}^{\mathrm{D}}$ the utility it can reach by defaulting at $T$. $V_{T}$ is the maximum of $V_{T}^{\mathrm{R}}$ and $V_{T}^{\mathrm{D}}$, and is thus the maximum utility achievable at time $T$. We assume that when repudiation and repayment yield exactly the same 
utility (i.e., $V^{\mathrm{D}}=V^{\mathrm{R}}$ ), the country repays the debt. Let us call $h_{T}()$ the lending limit which keeps the country from defaulting at $T . h_{T}$ is defined implicitly by the condition

$$
D_{T} \leqq h_{T}\left(K_{T}\right) \Leftrightarrow V_{T}^{\mathrm{R}}\left(K_{T}, D_{T}\right) \geqq V_{T}^{\mathrm{D}}\left(K_{T}\right) .
$$

From (17) and (18), $h_{T}$ is simply

$$
h_{T}\left(K_{T}\right)=\lambda a K_{T} /(1+r) \text {. }
$$

Thus, the country will repay $D_{T}$ if and only if $D_{T} \leqq h_{T}\left(K_{T}\right)=\lambda a K_{T} /(1+r)$.

Let us now analyze the problem at time $T-1$. We define $V_{T-1}^{\mathrm{R}}\left(D_{T-1}, K_{T-1}\right)$ as

$$
V_{T-1}^{\mathrm{R}}\left(D_{T-1}, K_{T-1}\right)=\max _{C_{T-1}, I_{T-1}, D_{T}}\left\{\log C_{T-1}+\beta V_{T}\left(K_{T}, D_{T}\right)\right\},
$$

subject to

$$
\begin{aligned}
& K_{T}=I_{T-1}+(1-d) K_{T-1}, \\
& J_{T}=\left[1+(1 / 2) \phi\left(I_{T-1} / K_{T-1}\right)\right] I_{T-1}, \\
& D_{T}=(1+r) D_{T-1}+C_{T-1}+I_{T-1}\left[1+(\phi / 2)\left(I_{T-1} / K_{T-1}\right)\right]-Q_{T-1},
\end{aligned}
$$

and

$$
D_{T} \leqq h_{T}\left(K_{T}\right) \text {. }
$$

$V_{T-1}^{\mathrm{R}}\left(K_{T-1}, D_{T-1}\right)$ is the utility that the country can reach by repaying the debt, $D_{T-1}$, when it faces a new supply of credit which is constrained by $D_{T} \leqq h_{T}\left(K_{T}\right)$.

Let us finally define

$$
V_{T-1}\left(D_{T-1}, K_{T-1}\right)=\max \left\{V_{T-1}^{\mathrm{R}}\left(K_{T-1}, D_{T-1}\right), V^{\mathrm{D}}\left(K_{T-1}\right)\right\},
$$

with $V_{T-1}^{\mathrm{D}}\left(K_{T-1}\right)$ the utility level that the country can reach by defaulting on the debt $D_{T-1} . V_{T-1}$ is the best outcome that the country can reach at time $t$ given its ability to repudiate the debt. We now define $h_{T-1}()$ as the rule which will keep the country from defaulting at time $T-1$. We want

$$
D_{T-1} \leqq h_{T-1}\left(K_{T-1}\right) \Leftrightarrow V_{T-1}^{\mathrm{R}}\left(K_{T-1}, D_{T-1}\right) \geqq V_{T-1}^{\mathrm{D}}\left(K_{T-1}\right) .
$$

By backward recursion, we can clearly define a sequence of lending rules $\left\{h_{T}(), h_{T-1}(), \ldots, h_{0}()\right\}$ such that (22) holds for all $t \geqq 1$, and $V_{t}^{\mathrm{R}}, V_{t}^{\mathrm{D}}$ and $V_{t}$ defined analogously to the expressions in (20) and (21). Eq. (22), when generalized for all $t$, is the condition for the country to repay its debt $D_{t}$ 
falling due at time $t$ when it expects at time $t, \ldots, T$, the lending rules $h_{t}, \ldots, h_{T}$ to apply.

It is interesting to consider the case when $\lambda=1$, i.e., when all output is lost in the event of default. In this case, a default at time $t$ results in $C_{t+i}=0$ for all $i \geqq 0$. Thus, $\lambda=1$ is tantamount to assuming that the country has no option to repudiate. It is easy to see that the planner will always choose to service the debt as long as it is feasible to pay $(1+r) D_{t}$ out of net exports at time $t$ plus new borrowing. At $T-1$, therefore, lenders limit loans $D_{T}$ such that $(1+r) D_{T} \leqq a K_{T}$ (clearly, for $(1+r) D_{T}>a K_{t}$, repayment in period $T$ is not feasible, as there is no lending in $T+1)$. At $T-2$, lenders require that (1 $+r) D_{T-1} \leqq \max \left(a K_{T-1}-J_{T-1}+D_{T}\right)$, such that $D_{T} \leqq a K_{T} /(1+r)$. Thus, $(1+r) D_{T-1} \leqq \max \left[a K_{T-1}-J_{T-1}+a K_{T} /(1+r)\right]$. In other words, $(1+r) D_{T-1}$ will be kept less than or equal to the maximum productive wealth at time $T-1$. By induction, it is easy to prove this result for all $t \leqq T$

$$
(1+r) D_{t} \leqq \max \sum_{i=t}^{T}\left(a K_{i}-J_{i}\right)(1+r)^{-(i-t)} \quad \text { subject to (2), (4), }
$$

or, using earlier notation

$$
(1+r) D_{t} \leqq \max W_{t}
$$

To sum up, when $\lambda=1$, borrowing is limited only by the maximum productive wealth of the economy.

\subsection{A digression on the precommitment of capital installation}

In the maximization problem which we set in (20), we implicitly assumed that the investment and borrowing decisions are made simultaneously, since the lenders at time $t$ can condition their loans on the investment decision of the country. The loan at time $t, D_{t+1}$, is therefore made a function of the capital stock that will be in place at time $t+1$. If the lending decision must be made before $I_{t}$ is observed, there is a moral hazard problem. The country, even if it wishes to precommit itself to investing a certain amount $I_{t}$ in light

of the borrowing constraint $D_{t+1} \leqq h_{t+1}\left(K_{t+1}\right)$, may find it profitable not to do so after the loan has been granted. In such situations, the lending strategy by the banks should be written

$$
D_{t} \leqq h_{t}\left(K_{t-1}\right)
$$

and the borrower will typically reach a lower level of utility because of this lagged relationship. In all that follows, we shall ignore this problem by assuming that the loan can be predicated on the investment decision each 
period. We refer the reader to our previous work (1984) for further discussion.

\subsection{Infinite-horizon economies}

When one lets the time horizon of the economy go to infinity, the definition of the lending rule remains the same except that the time subscript may be dropped, since $h_{t}\left(K_{t}\right)$ will be the same for all $t$. An equilibrium will be defined by the four functions $V^{\mathrm{D}}\left(K_{t}\right), V^{\mathrm{R}}\left(K_{t}, D_{t}\right), V\left(K_{t}, D_{t}\right)$ and $h\left(K_{t}\right)$, such that

$$
V^{\mathrm{R}}\left(D_{t}, K_{t}, h()\right)=\max _{C_{t}, I_{t}, D_{t+1}}\left[\log C_{t}+\beta V\left(D_{t+1}, K_{t+1}, h()\right)\right]
$$

subject to (2), (4), (13) and

$$
\begin{aligned}
& D_{t+1} \leqq h\left(K_{t+1}\right), \quad V\left(D_{t}, K_{t}\right)=\max \left\{V^{\mathrm{R}}(), V^{\mathrm{D}}()\right\}, \\
& D_{\imath} \leqq h\left(K_{t}\right) \Leftrightarrow V^{\mathrm{R}}\left(K_{t}, D_{t}, h()\right) \geqq V^{\mathrm{D}}\left(K_{t}\right) .
\end{aligned}
$$

$h()$ is therefore a stationary rule such that if future lenders are to apply it as a criterion for future lending, it will also be used as a criterion for current lending.

Before proceeding to the specific solution for $V^{\mathrm{D}}, V^{\mathrm{R}}$, and $h$ in the case of $\lambda<1$, it is useful to make one small amendment to (25). Though $V^{\mathrm{R}}$ equals $\log C_{t}+\beta V_{t+1}$, and $V_{t+1}=\max \left(V_{t+1}^{\mathrm{R}}, V_{t+1}^{\mathrm{D}}\right)$, the lending constraint $D_{t+1} \leqq h\left(K_{t+1}\right)$ guarantees that $V_{t+1}^{\mathrm{R}} \geqq V_{t+1}^{\mathrm{D}}$ as long as the debt is repaid at time $t$. In other words, as long as the debt is repaid once, borrowing constraints will guarantee that all future debts will also be repaid (this is true only in a model without uncertainty). Therefore, $V^{\mathrm{R}}$ in (25) will also satisfy

$$
V^{\mathrm{R}}\left(D_{t}, K_{t}\right)=\max \left[\log C_{t}+\beta V^{\mathrm{R}}\left(D_{t+1}, K_{t+1}\right)\right]
$$

where $V^{R}$ replaces $V$ on the right-hand side.

One case of $(25)$ is easily solved: for $\lambda=1$. As noted earlier, $(1+r) D_{t}$ will always be repaid as long as repayment is feasible out of net exports $a K_{t}-J_{t}$ and new borrowing $D_{t+1}$, i.e., as long as $(1+r) D_{t} \leqq \max \left(a K_{t}-J_{t}+D_{t+1}\right)$. Of course, $D_{t+1}$ is limited by $D_{t+1} \leqq h\left(K_{t+1}\right)$. Thus, the borrowing constraint is defined by a stationary $h$ function, such that $h\left(K_{t}\right)=\left[\max \left(a K_{t}-J_{t}+D_{t+1}\right)\right] /$ $(1+r)$, with $D_{t+1} \leqq h\left(K_{t+1}\right)$. Upon substitution, for $D_{t+1}$ we have $h\left(K_{t}\right)=$ $\max \left[a K_{t}-J_{t}+h\left(K_{t+1}\right)\right] /(1+r)$. The solution to this functional equation is

$$
h\left(K_{t}\right)=\max \left[\sum_{i=t}^{\infty}(1+r)^{-(i-t)}\left(a K_{i}-J_{i}\right)\right] /(1+r)=\max W_{t} /(1+r) .
$$


Thus, as in the case of finite $T$, the borrowing constraint when $\lambda=1$ is simply that $D_{t}(1+r)$ must be less than or equal to the maximum value of national productive wealth.

For $\lambda=1$, the problem in (24) reduces to the standard borrowing problem without repudiation risk

$$
\max \sum_{t=0}^{\infty} \beta^{t} \log C_{t}
$$

subject to (2), (4), (13), $D_{0}=0, K_{0}$ given and, for all $t$,

$$
D_{t}(1+r) \leqq \max \sum_{i=t}^{\infty}\left(a K_{i}-J_{i}\right)(1+r)^{-(i-t)} .
$$

It is a standard exercise to show under these circumstances that the optimal production decision and the consumption choice can be separated. Given the international rate of interest, investment is chosen to maximize the productive wealth of the country. Given the path of productive wealth, the planner then selects an optimal pattern of consumption, subject only to the constraint that $D_{t}(1+r) \leqq \max W_{t}$ is satisfied. We show in Appendix 3 that the equilibrium will be characterized by the two following conditions:

Proposition 1. When $\lambda=1$ (i.e., the country can never profitably repudiate its debt)

(1) GDP grows at the fixed rate $g^{*}[e q .(8)]$ which maximizes productive wealth,

(2) consumption grows at a rate $\theta=\beta(1+r)-1$.

The initial value of consumption is defined so that the discounted value of the infinite sequence of consumption is equal to the wealth of the country.

Under the assumption (12), consumption over GDP tends to zero in the stationary state. This says that in the long run all GDP goes to repayment of the debt. When the country has the option to repudiate its debt, even at a substantial loss, a path in which consumption asymptotically approaches zero, as a fraction of GDP, can never be an equilibrium since the option to repudiate would eventually be exercised. Lenders will restrain their lending so that in the limit only a fraction of GDP goes to the repayment of the debt, and so that consumption does not tend to zero in the long run.

One additional feature of the equilibrium is the following. The productive wealth of the economy $W_{t}$ is maximized by the investment path, and it grows at the same rate as GDP, i.e., at the rate $g^{*}$. Since $g^{*}<r$ (by our earlier assumptions on the technology parameters), and since $(1+r) D_{t} \leqq W_{t}$ by the 
lending rule, we see that $D_{t}$ must grow less rapidly than rate $r$ in the long run. Therefore, the path of $(1+r) D_{t}$ satisfies the so-called 'transversality condition'

$$
\lim _{t \rightarrow \infty} D_{t} /(1+r)^{t}=0
$$

Let us define $R P_{t}$ as the net repayment of debt each period, given by the difference of $(1+r) D_{t}$ and new borrowing $D_{t+1}$

$$
R P_{t}=(1+r) D_{t}-D_{t+1}
$$

Since (29) implies $D_{t+1}=(1+r)^{t+1} D_{0}-\sum_{i=0}^{t}(1+r)^{(t-i)} R P_{i}$, we have $D_{t+1} /$ $(1+r)^{t}=(1+r) D_{0}-\sum_{i=0}^{t}(1+r)^{-i} R P_{i}$. Then, taking limits and applying the transversality condition, we have

$$
(1+r) D_{0}=\sum_{i=0}^{\infty}(1+r)^{-i} R P_{i}
$$

In effect, the transversality condition is a zero-profit condition for the sequence of loans: it guarantees that the discounted value of repayments equals the outstanding debt payment due at time $t,(1+r) D_{t}$.

We have found the transversality condition to be implied by the market equilibrium. If lenders expect $(1+r) D_{t+i} \leqq W_{t+i}$ for all $i>0$, they will impose $(1+r) D_{t+1} \leqq W_{t+1}$ in period $t$. In some models, the transversality condition need not be an implication of market equilibrium [see Cohen and Sachs (1985) as an example]. Later in this paper, in section 4, we will need to impose the zero-profit condition (30) directly, rather than finding it as an implication of the model.

\subsection{Market equilibrium with repudiation risk}

We now turn to the case of $\lambda<1$, and show that the lending rule $h\left(K_{t}\right)$ is linear in $K_{t}$. The equilibrium path, when $\lambda<1$ is described by the following proposition:

Proposition 2. Lending in each period is governed by a linear credit constraint

$$
D_{t} \leqq h^{*} K_{t}
$$

where $h^{*}$ is a constant which depends both on the technology of production and on the taste parameters of the intertemporal utility function. Given this constraint, a country with no initial debt selects a path with two stages 
Stage 1. The constraint (3I) on the debt is not binding. The rate of growth of the economy is high initially, and declines progressively, and the debt-to-GDP and debt-to-capital ratios increase.

Stage 2. The constraint on the debt is binding. The economy and the debt grow at a same rate $n$, which is lower than the growth rates in Stage 1 and below the rate of growth, $g^{*}$, which maximizes productive wealth.

According to Proposition 2, the threat of repudiation forces the economy into an equilibrium with productive inefficiency, since the rate of growth in Stage 2 is below the level $g^{*}$ which maximizes productive wealth. With debt growing at rate $n$, we have $D_{t+1}=(1+n) D_{t}$. Also, $D_{t+1}=(1+r) D_{t}-R P_{t}$, where $R P_{t}$ is the amount of repayment at time $t$. Thus, $R P_{t}=(r-n) D_{t}$, or

$$
R P_{t}=\theta Q_{t} \text { with } \theta=(r-n) h^{*} / a
$$

One sees that the repayment is always less than the amount of interest falling due, $r D_{t}$, so that the lenders always refinance some interest payments. Despite this property, the discounted value of debt repayments equals $(1+r) D_{t}$, i.e., the zero profit condition in (3) holds. [We know this to be true, since with debt growing at rate $n<r$, the transversality condition in (28) is satisfied.]

Once the binding debt-to-capital ratio, $h^{*}$, has been reached, the only way the lenders can keep the country from defaulting is to continue to lend according to the same rule. If they cease to do so, and demand, for example, the repayment of all interest falling due, then the country will default. (Proof. The rule $D^{*} \leqq h^{*} K$, when it is binding, leads by construction to $V^{\mathrm{D}}=V^{\mathrm{R}}$. Any tighter lending rule will then have $V^{\mathrm{D}}>V^{\mathrm{R}}$, and the country will default.)

The proof of Proposition 2 is given in Appendix 3. Here we sketch the main steps of the proof. First, we guess a function for $\tilde{h}(K)$ and solve the optimal borrowing problem under the constraint $D_{t} \leqq \widetilde{h}\left(K_{t}\right)$, assuming no debt repudiation. The optimal borrowing problem yields an optimal consumption plan, $\left\{C_{t}^{\tilde{h}}\right\}$, where the superscript $\tilde{h}$ stresses the dependence of the optimal plan on the assumed borrowing constraint. We then define the value of the optimal program (under $\tilde{h}$ ) as $V^{\hat{h}}\left(K_{t}, D_{t}\right)=\sum_{i=0}^{\infty} \beta^{t+i} \log \left(C_{t+i}^{\bar{h}}\right)$. By construction, $\mathrm{V}^{\hbar}$ satisfies the eq. $\left(25^{\prime}\right): V^{\hbar}\left(K_{t}, D_{t}\right)=\max \left(\log \left(C_{t}\right)+\right.$ $\left.\beta V^{\tilde{h}}\left(K_{t+1}, D_{t+1}\right)\right)$ such that $D_{t+1} \leqq \tilde{h}\left(K_{t+1}\right)$. Then, we prove for our choice $\tilde{h}$ that $D_{t+1} \leqq \widetilde{h}\left(K_{t+1}\right)$ if and only if $V^{h}\left(K_{t}, D_{t}\right) \geqq V^{\mathrm{D}}\left(K_{t}\right)$. Thus, we have found a solution to (25), with $V^{\mathrm{R}}=V^{\tilde{h}}, h=\tilde{h}$, and $V^{\mathrm{D}}=V^{\mathrm{D}}$. Using $C_{t}^{\hat{h}}$, we then prove the part of the proposition concerning the two-stage growth path.

Specifically, we prove that the linear credit rule in (31) satisfies the market equilibrium in (25). The properties of the borrowing equilibrium under $D_{t} \leqq h^{*} K_{t}$ are easy to calculate, as shown in Appendix 3. We solve the optimal control problem for foreign borrowing subject to the constraint that 
$D_{t} \leqq h^{*} K_{t}$. The result is the two-stage growth process described in Proposition 2. Starting $D_{0}=0$, there is an initial period of rapid but declining growth, with $D / K$ rising to $h^{*}$. Once the constraint is binding, $D / K$ remains equal to $h^{*}$, and growth remains equal to $x^{h^{*}}$, where $x^{h^{*}}$ is the root of eq. (A3.8) in Appendix 3. The growth rate is less than $g^{*}$, the growth rate that maximizes $W_{t}$. (Remember that $g^{*}$ is achieved when $\lambda=1$, i.e., when there is no viable threat of repudiation.)

In Appendix 3, we present the non-linear eq. (A3.12) that defines $h^{*}$. It is straightforward to show that $h^{*}$ is: increasing in $a, \beta$, and $\lambda$; and is decreasing in $r$. In words, the sustainable debt per unit of capital rises with capital productivity, the discount factor, and the penalty for default, while it falls with the world interest rate. By a simple transformation, the maximum debt-GNP ratio is a similar function of these variables, since $D / G N P=$ $D /[a K-r D)$, which must be less than or equal to $h /(a-r h)$ when $D \leqq h K$. In table 1 , we calculate the maximum debt-GNP ratios for alternative values of $a, \beta, \lambda$, and $r$.

Table 1a

Maximum debt-GNP ratios: Alternative values of capital productivity, $a$, and subjective discount rate, $\beta$ (for $r=0.1, \lambda=0.4$ ). ${ }^{\mathrm{a}}$

\begin{tabular}{|c|c|c|c|c|}
\hline \multirow[b]{2}{*}{$a$} & \multicolumn{4}{|l|}{$\beta$} \\
\hline & 0.6 & 0.7 & 0.8 & 0.9 \\
\hline 0.15 & 2.31 & 2.48 & 2.82 & 3.75 \\
\hline 0.20 & 2.44 & 2.68 & 3.15 & 4.55 \\
\hline 0.25 & 2.61 & 2.92 & 3.60 & 5.89 \\
\hline 0.30 & 2.81 & 3.23 & 4.24 & 9.28 \\
\hline
\end{tabular}

Table $1 b$

Maximum debt-GNP ratios: Alternative values of world interest rate, $r$, and default penalty rate, $\lambda$ (for $a=0.2, \beta=0.9$ ).

\begin{tabular}{|c|c|c|c|c|}
\hline \multirow[b]{2}{*}{$r$} & \multicolumn{4}{|l|}{$\lambda$} \\
\hline & 0.1 & 0.2 & 0.3 & 0.4 \\
\hline 0.10 & 0.95 & 2.02 & 3.22 & 4.55 \\
\hline 0.15 & 0.67 & 1.42 & 2.28 & 3.26 \\
\hline 0.20 & 0.51 & 1.10 & 1.78 & 2.58 \\
\hline 0.25 & 0.41 & 0.90 & 1.46 & 2.14 \\
\hline
\end{tabular}

${ }^{\text {a }}$ The other parameter values are $d=0.05$, $\phi=10$. 
It is also instructive to compare the equilibrium growth paths for GDP under alternative borrowing assumptions, as is done in fig. 1. The dashed line, which increases most rapidly, is for GDP in the absence of repudiation risk (i.e., for $\lambda=1$ ); the solid line, which shows intermediate growth, is for $G D P$ with repudiation risk (specifically, $\lambda=0.4$ ), with $D / K$ initially below $h^{*}$; the dotted line, with the slowest growth, represents the case without foreign borrowing (either a closed economy, or open economy with $\lambda=0$ ). There are two notable aspects of the figure. First, it is apparent that productive wealth is reduced by the option to repudiate. Second, we see the point of inflection (in period 17) in the intermediate growth path, which according to Proposition 2 is reached when the constraint $D_{t} \leqq h^{*} K_{t}$ begins to bind.

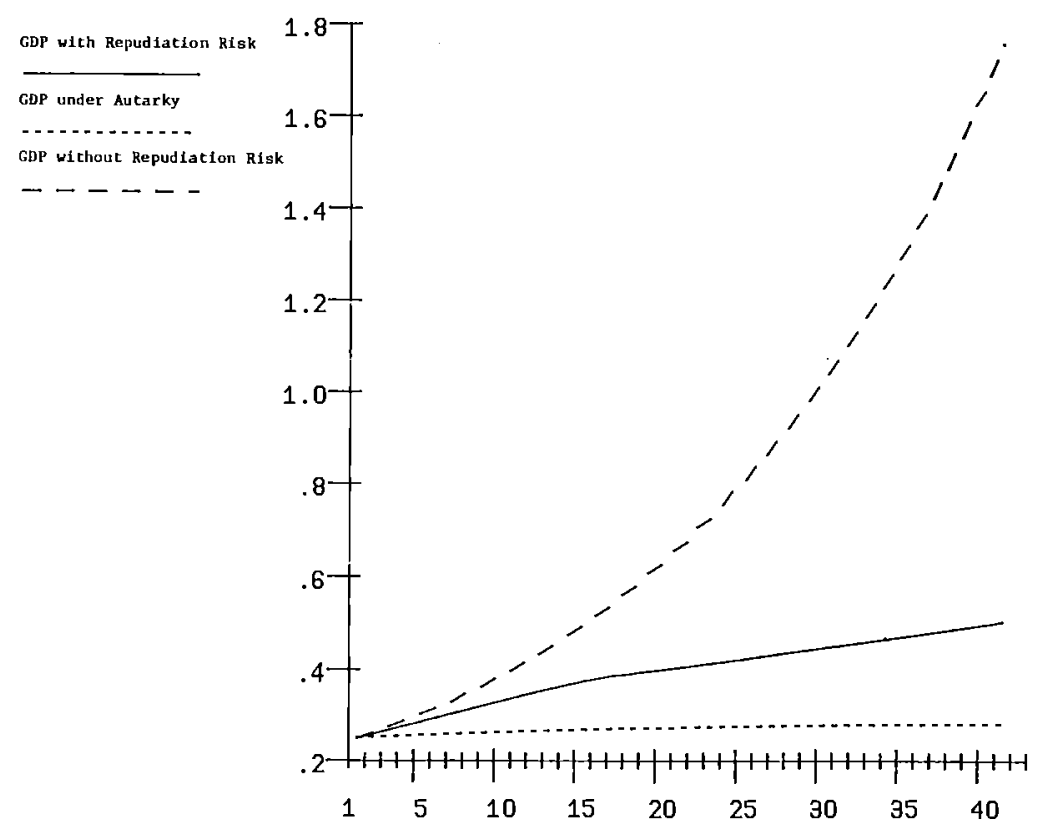

Fig. 1. GDP under alternative borrowing assumptions.

\section{Equilibrium with repudiation in non-linear models}

We have been able to derive a closed-form solution for the growth path in the case $Q_{t}=a K_{t}$ because the value function $V^{\mathrm{R}}$ is separable in $K$ and $D$ (see Appendix 3). This separability arises because two economies with the same $D_{t} / K_{t}$ but different $K_{t}$ will differ only in scale. With $D_{t}^{1} / K_{t}^{1}=D_{t}^{2} / K_{t}^{2}$ and $K_{t}^{2}=K_{t}^{1}$, economy 2 will simply follow a path in which all variables $\left(C_{t}^{2}, D_{t}^{2}\right.$, $\left.K_{t}^{2}, G D P_{t}^{2}\right)$ are equal to $D_{t}^{2} / D_{t}^{1}$ times the values in economy $1\left(C_{t}^{1}, D_{t}^{1}, K_{t}^{1}\right.$, $\left.G D P_{t}^{1}\right)$. 
Once the linear production technology is abandoned, an analytical solution appears out of reach. Now, a rise in $K$ is more than a scale change, since output does not (by assumption) rise in the same proportion. For a standard neoclassical production technology, $Q_{t}=F\left(K_{t}\right)$, with $F^{\prime}>0, F^{\prime \prime}<0$, a rise in $K_{t}$ lowers the marginal product of capital and reduces the incentive to invest. It is not surprising, therefore, that the maximum $D_{t}$ associated with $K_{t}$ will not rise in equiproportion with $K_{t}$. In other words, the $h$ function giving $D_{t}, h\left(K_{t}\right)$ will be less than unit elastic in $K_{t}$.

In order to investigate this case, we resort to numerical dynamic programming methods (designed by Mr. Atish Ghosh in conjunction with the authors). Specifically, the value function $V^{\mathrm{D}}\left(K_{t}\right)$ is calculated numerically for a grid on $K_{t}$ varying between 0 and 10.0 , with steps of 0.1 . Then, $V^{\mathrm{R}}\left(K_{t}, D_{t}\right)$ is calculated using the backward recursion methodology outlined in section 3. The $V^{\mathrm{R}}$ function is analyzed on a grid of 0 to 10.0 for $K_{t}$, and 0 to 2.0 for $D_{t}$, both with step sizes of 0.1 . Once $V_{T-t}^{\mathrm{D}}$ and $V_{T-t}^{\mathrm{R}}$ are calculated for a period of $T-t$, as in section 3 , the optimization in (20) is carried out by a numerical search procedure over $I$ and $C$, using step sizes of 0.05 for these variables. The backward recursion procedure is repeated until $V^{\mathrm{D}}$ and $V^{\mathrm{R}}$ converge to steady-state functions within the specified tolerance.

An example of this numerical exercise is shown in figs. 2 and 3. We adopt a Cobb-Douglas production technology $Q_{t}=3 K_{t}^{0.3}$. Fig. 2 plots the maximum debt/GDP ratio as a function of $G D P$. (Note that the jagged nature of the curve results only from the discrete step-sizes used in the programming algorithm. These minor blips are unimportant quantitatively. A smoother curve could be achieved by a finer grid size, but at the cost of much higher computing time.) ${ }^{1}$ In the linear case, of course, this maximum ratio is a constant $\left(h^{*} / a\right)$, independent of the level of GDP. In the case of $\mathrm{Cobb}-\mathrm{Douglas}$ technology, however, the maximum ratio declines as GDP increases. This is for a straightforward, yet illuminating reason. At low levels of $G D P$, the marginal productivity of capital is very high and the investment incentives are consequently strong. The returns to borrowing abroad are large, as are the costs of debt repudiation (which would freeze out new borrowing to finance further increases in $K$ ). As the capital stock deepens, the incremental returns to investment fall, and the costs of debt repudiation as a fraction of GDP are reduced pari passu. Thus, a capital-poor country will be allowed a wide latitude in foreign borrowing, while a capitalabundant economy will be much more restricted (as a proportion. of $G D P$ ). The allowable debt rises as GDP rises but less than proportionately.

\footnotetext{
${ }^{1}$ With the grid selected, there are two thousand points in the domain of $V_{l}^{\mathrm{R}}\left(K_{t}, D_{t}\right)$. An optimization must be performed at each of these points for each period in which $V_{l}^{\mathrm{R}}$ is evaluated. Even with the coarse grid that has been used, the evaluation of $V^{\mathrm{R}}$ and $V^{\mathrm{D}}$ requires substantial computer time.
} 


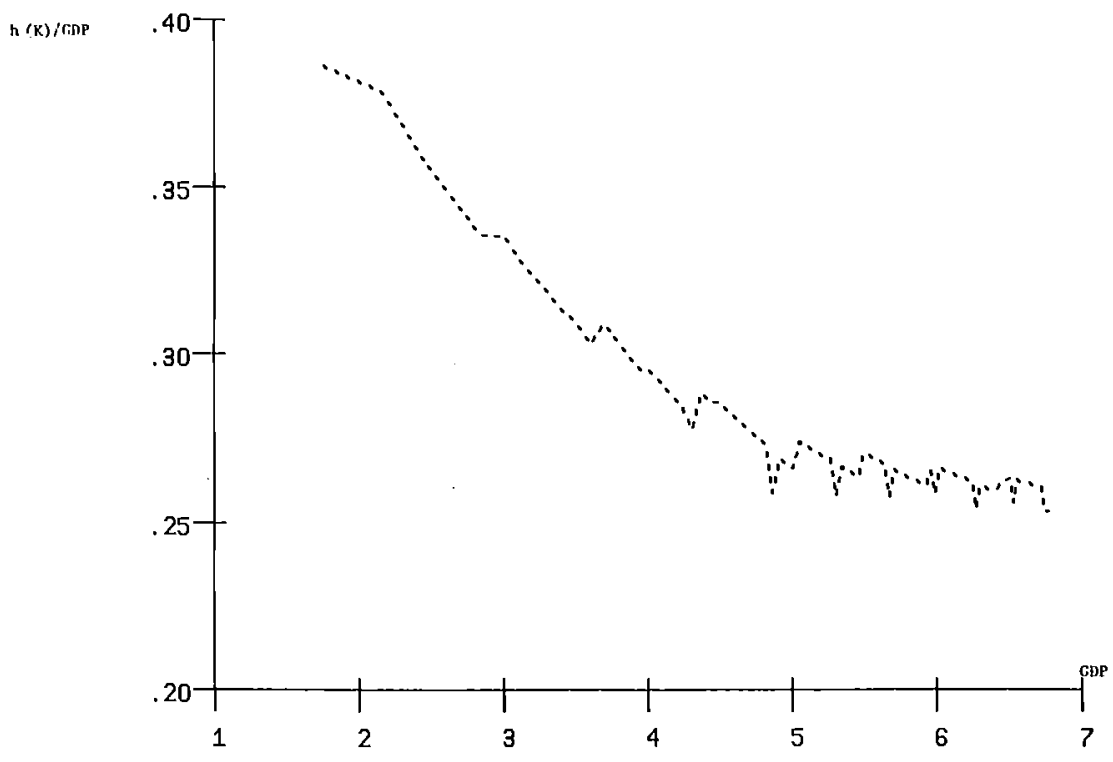

Fig. 2. Maximum debt-to-GDP ratio.

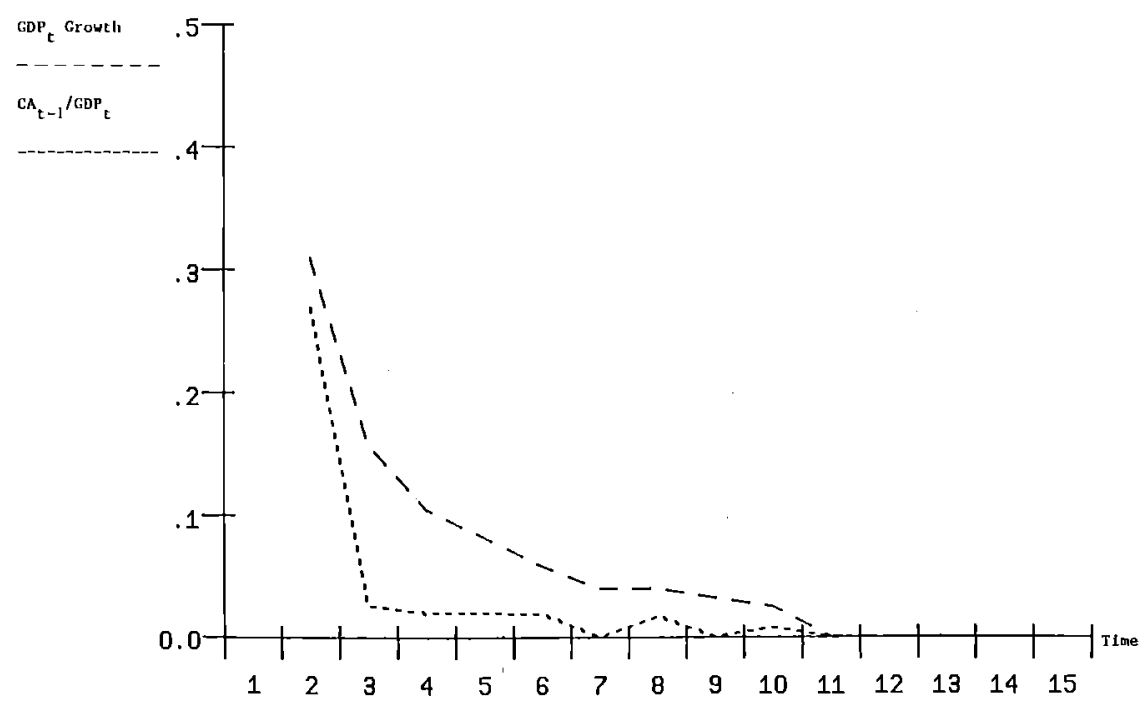

Fig. 3. GDP growth and current account deficits (GDP, growth is $\left(Q_{t}-Q_{t-1}\right) / Q_{t-1}$; $\mathrm{CA}_{t-1} / \mathrm{GDP}_{t}$ is $\left.\left(D_{t}-D_{t-1}\right) / Q_{t}\right)$. 
As shown in figs. 3 and 4, this feature of the $h($ ) function has important implications for the growth path and for foreign borrowing. As in the linear model, growth and foreign borrowing start out high and then fall sharply as the debt constraint is hit (in this case as of period 2). Fig. 3 shows the GDP growth rate and the current account deficit as a percentage of GDP. Fig. 4 shows the actual and maximum debt-GDP ratios for periods 1 through 15. In each period, the maximum rate is calculated as $h\left(K_{t}\right) / G D P_{t}$ where $K_{t}$ is the level of $K_{t}$ on the equilibrium growth path. In the first period, actual $D_{t} / G D P_{t}<h\left(K_{t}\right) / G D P_{t}$. In periods 2 through 15 , the debt constraint is binding as shown. Note that the debt-GDP ratio jumps sharply between periods 1 and 2, and then declines over, as the country becomes wealthier (i.e., as the capital stock deepens). The decline reflects the already observed fact that $h\left(K_{t}\right) / G D P_{t}$ is a declining function of $K_{t}$.

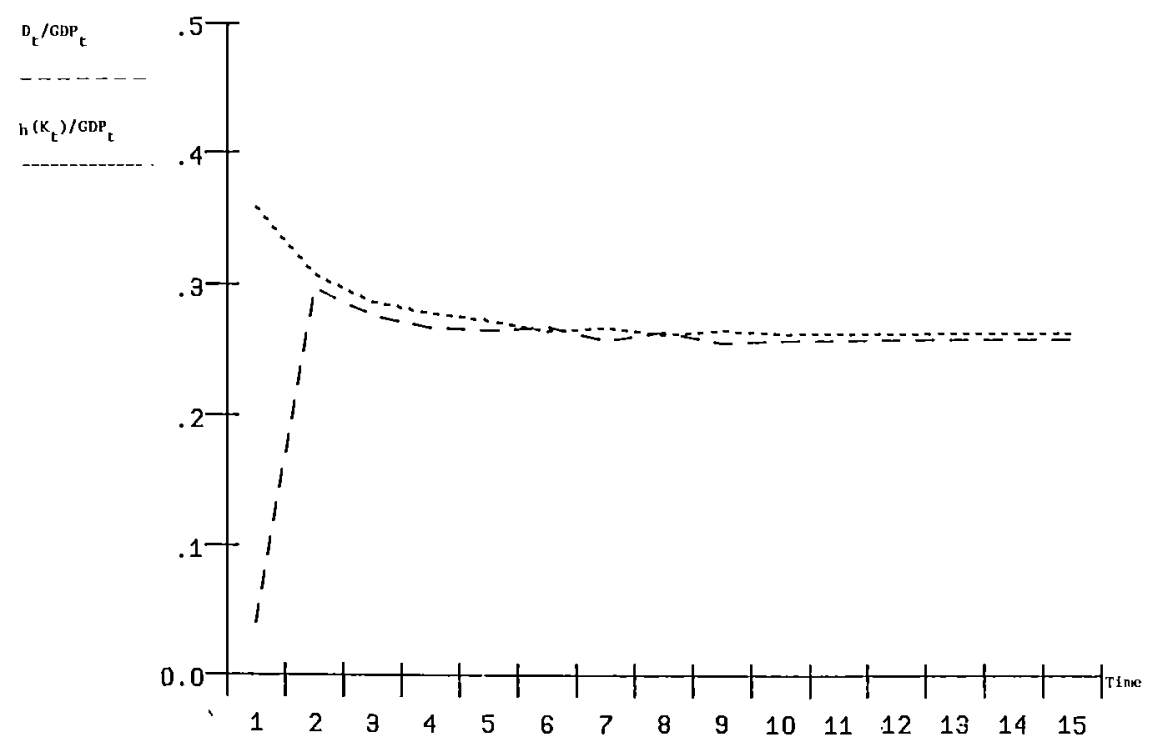

Fig. 4. Actual and maximum debt-GDP ratios.

\section{Alternative lending strategies}

In this section we return to the linear version of the model in order to examine lending and repayment strategies which differ from the market equilibrium described above. In the first subsection, we assume that the lenders and the borrower can act cooperatively to decide upon a path of future debt, consumption and investment, subject only to the zero profit condition in (3) and to the condition that the country keep its sovereign right to repudiate the debt at any time and to suffer the penalty thereafter. (If the 
country can also credibly promise never to repudiate, it reaches the equilibrium of Proposition 1.) Is there any contractual scheme between the lenders and the borrower that can dominate the market equilibrium and still keep the country from defaulting? The answer is no, as we show in the proof of Proposition 3.

In the second subsection, we analyze a repayment scheme which has been suggested by some analysts. We have seen that when $D_{t}=h^{*} K_{t}$, in Stage 2 of the market equilibrium, the country repays every period a fixed fraction $\theta$ of $G D P$, as in (32). What if the lenders simply demand that $R P_{t}=\theta Q_{t}$, rather than sticking to the rule $D_{t}=h^{*} K_{t}$ ? It turns out that when the borrower expects to face the rule $R P_{t}=\theta Q_{t}$ rather than the rule $D_{t}=h^{*} K_{t}$, the incentives for growth are changed in a way that undermines this alternative lending rule.

\subsection{Contractual agreements between the lenders and the borrower}

In this subsection, we assume that the borrowing country and its lenders can design a path of future debt, investment and consumption such that (i) the loan satisfies the zero-profit condition (30), and (ii) the country never finds it profitable to repudiate its debt. The path is set once and for all at $t=0$. Surprisingly, such a contractual arrangement cannot dominate the market equilibrium.

Proposition 3. The market equilibrium yields the optimal pattern of growth that a country can reach, subject to the constraint that it never prefers to default.

The proposition says, among other things, that there is no way to avoid the slowdown of growth described in Proposition 2. This slowdown is an inherent implication of the option of repudiation; there is no way that the country can credibly promise to grow at $g^{*}$ forever.

To prove Proposition 3, we first define new utility function $\Omega$ which would be attained if the country can design in advance its path of consumption and investment subject to (3) and the constraint that it never prefer to default.

$$
\Omega\left[D_{0}, K_{0}\right]=\max _{\left\{C_{t}, I^{\prime}, D_{t}\right\}} \sum_{t=0}^{\infty} \beta^{t} \log C_{t},
$$

subject to (2), (4). (13), (30), transversality condition (16), and

$$
\sum_{(t=s)}^{\infty} \beta^{(t-s)} \log C_{t} \geqq V^{\mathrm{D}}\left(K_{s}\right)
$$

Note that (34) guarantees that the country will never choose to repudiate the 
debt. A priori, $\Omega$ does not coincide with the utility $V$ achieved in the market equilibrium. $V$ was defined as the fixed point of problem (25). $\Omega$ is defined directly by an optimizing problem. They in fact are equal, as we show in Appendix 4. The crux of the argument is to show that inequality (34) can be written $D_{t} \leqq h^{*} K_{t}$, as in the market equilibrium case.

\subsection{Repayment of a fixed fraction of the revenues each period}

Let us assume that the country has already entered Stage 2 of its pattern of growth. Each period, it repays a fixed fraction of its revenues to the lenders in order to equalize the growth of debt and the growth of GDP. These repayments can be written $R P_{t}=\left[(r-n) h^{*} / a\right] Q_{t}$, with $n=x^{h^{*}}-d$, where $x^{h^{*}}$ is the investment rate in Stage 2.

Now, let us assume that the lenders ask to be repaid some fraction $\tilde{\theta}$ of $G D P$, instead of sticking to the original rule of lending $D \leqq h^{*} K$. $\tilde{\theta}$ may or may not equal $(r-n) h^{*} / a$. We prove the following:

Proposition 4. When a country has reached the Stage 2 of its pattern of growth, the lenders cannot get repayment of their loans by abandoning the rule $D_{t} \leqq h^{*} K_{t}$ and by asking instead to be repaid a fixed fraction of the country's GDP each period. By doing so, they would either induce the country to default, or they would get repayment of only a portion of the outstanding debt [i.e., the zero profit condition in (3) would not hold].

The proposition stresses the importance to the creditors of stating correctly the rule governing their lending. In the market equilibrium, the lenders are ready to increase their exposure at the rate of GDP growth. By doing so, they create an incentive for the country to grow. Any slight modification of the rule which reduces this incentive to grow yields a sub-optimal result. A repayment scheme as in Proposition 4 creates an incentive that is adverse to growth, since debt repayments are made an increasing function of the output of the economy.

To prove Proposition 4, assume that the country is asked to repay a fixed fraction $\tilde{\Theta}$ of its GDP. It will select an optimal rate of growth by solving

$$
\begin{aligned}
V_{\tilde{\theta}}=\max _{x}\{ & \log [a(1-\tilde{\Theta})-x(1+\phi x / 2)] /(1-\beta) \\
& \left.+\beta[\log (1+x-d)] /(1-\beta)^{2}+\log K_{0} /(1-\beta)\right\} .
\end{aligned}
$$

[See eq. (A1.8) where $a \tilde{\Theta}$ is substituted for $\lambda$.

Let $x_{\bar{\theta}}$ be the solution to (35). We can compute the value of this repayment stream by noting that $R P_{t+1}=\widetilde{\Theta} G D P_{t+i}=\widetilde{\Theta} a K_{t+i}=\widetilde{\Theta} a\left(1+x_{\tilde{\theta}}-d\right)^{i} K_{t}$. 
Thus, the discounted value of repayments, which we denote by $P_{t}$, is given as

$$
\left.P_{t}=\sum_{i=t}^{\infty} R P_{t} /(1+r)^{i}=\left[a K_{t} \tilde{\Theta}(1+r)\right] / r-d-x_{\tilde{\Theta}}\right]
$$

Now, suppose $\widetilde{\Theta}$ is selected so that $P_{t}=(1+r) D_{t}$, i.e., so that the debt is repaid in present value terms. Call the selected value $\hat{\Theta}$. Since $D_{t}=h^{*} K_{t}$ by assumption, we must have $P_{t}=h^{*}(1+r) K_{t}$. Thus, from (36) we must have the equality $h^{*}=a \hat{\Theta} /\left[r+d-x_{\hat{\theta}}\right]$. From (35) we then see that

$$
\begin{aligned}
V_{\hat{\boldsymbol{\theta}}}= & \log \left[a-h^{*}\left(r+d-x_{\hat{\boldsymbol{\theta}}}\right)-x_{\hat{\theta}}\left(1+\phi x_{\hat{\theta}} / 2\right)\right] /(1-\beta) \\
& +\beta\left[\log \left(1+x_{\hat{\boldsymbol{\theta}}}-d\right)\right] /(1-\beta)^{2}+\log K_{t} /(1-\beta) .
\end{aligned}
$$

Now we prove that $V_{\hat{\theta}}<V^{\mathrm{D}}$, as asserted in Proposition 4. That is, we prove that the country would default if required to pay $\Theta G D P$, for $\Theta$ high enough to yield $P_{t}=(1+r) D_{t}$. By definition of $x^{h^{*}}$ and $h^{*}$ (at which the country is at autarky utility in the market equilibrium), we can use (37) to write

$$
\begin{aligned}
V^{\mathrm{D}}= & \log \left[a-h^{*}\left(r+d-x^{h^{*}}\right)-x^{h^{*}}\left(1+\phi x^{h^{*}} / 2\right)\right] /(1-\beta) \\
& +\beta\left[\log \left(1+x^{h^{*}}-d\right)\right] /(1-\beta)^{2}+\log K_{t} /(1-\beta) .
\end{aligned}
$$

Note that the right-hand side of (38) is the same as the right-hand side of (37) but with $x^{h^{*}}$ replacing $x_{\hat{\theta}}$. But $x^{h^{*}}$ maximizes the right-hand side of (37) for given $h^{*}$, so it must be $V^{\mathrm{D}}>V_{\hat{\boldsymbol{\theta}}}$. If the creditors are to be repaid, the borrower is driven below the autarky level.

\section{Conclusion}

We have constructed a model with endogenous growth and endogenous credit ceilings, We have shown that the equilibrium path for the country is one with initially rapid growth followed by a permanent slowdown. The equilibrium strategy of the lenders makes the growth of debt contingent on the growth of the borrowing country. In the linear version of our model, under the equilibrium lending rule, the evolution of the debt follows two stages, a first stage in which debt grows faster than the economy, and a second stage where both the economy and the debt grow more slowly, and at the same rate. Along this path, the interest due, $r D$, is never repaid in full; only an amount equal to the difference between the interest due and $g^{*} D$ (the growth rate times the debt) should be repaid. This permanent refinancing of part of the interest is the only way to reach the optimum pattern of growth consistent with no default by the borrowing country. 


\section{Appendix 1: Optimal growth under autarky}

The optimal growth problem under autarky is

$$
V_{t}\left(K_{0}\right)=\max \sum_{t=0}^{\infty} \beta^{t} \log \left(C_{t}\right)
$$

such that $K_{t+1}=K_{t}(1-d)+I_{t}, a K_{t}=C_{t}+I_{t}\left[1+(\phi / 2)\left(I_{t} / K_{t}\right)\right]$ and $K_{0}$ is given.

To solve this problem, we define $c_{t}=C_{t} / K_{t}, x_{t}=I_{t} / K_{t}$. Note that $K_{t+1}=$ $K_{t}\left(1-d+x_{t}\right)$, so that

$$
K_{t}=K_{0} \prod_{i=0}^{t-1}\left(1-d+x_{i}\right)
$$

and

$$
\log K_{t}=\log K_{0}+\sum_{i=0}^{t-1} \log \left(1-d+x_{i}\right)
$$

Since $c_{t}=C_{t} / K_{t}, \log C_{t}=\log c_{t}+\log K_{t}$. Hence,

$$
\begin{aligned}
\sum_{0}^{\infty} \beta^{t} \log \left(C_{t}\right)= & \sum_{0}^{\infty} \beta^{t} \log c_{t}+\sum_{0}^{\infty} \beta^{t} \log K_{t} \\
& =\sum_{0}^{\infty} \beta^{t} \log c_{t}+\sum_{0}^{\infty} \beta^{t} \log K_{0}+\sum_{0}^{\infty} \beta^{t}\left[\sum_{i=1}^{t-1} \log \left(1-d+x_{i}\right)\right] .
\end{aligned}
$$

After a bit of manipulation,

$$
\sum_{0}^{\infty} \beta^{t}\left[\sum_{i=0}^{t-1} \log \left(1-d+x_{i}\right)\right]
$$

can be rewritten as

$$
\sum_{t=0}^{\infty}\left[\beta^{t+1} /(1-\beta)\right] \log \left(1-d+x_{t}\right) .
$$

Thus, the original problem (A1.1) can be rewritten as

$$
V^{\mathrm{A}}\left(K_{0}\right)=\max \sum_{t=0}^{\infty} \beta^{t}\left\{\log c_{t}+\log K_{0}+[\beta /(1-\beta)] \log \left(1-d+x_{t}\right)\right\},
$$

such that $a=c_{t}+x_{t}\left[1+(\phi / 2) x_{t}\right]$.

Note that we have solved out for $K_{t}$ in the objective function, so we no longer need to include $K_{t+1}=K_{t}\left(1-d+x_{t}\right)$ among the constraints. Now 
there are no longer any real dynamic constraints in the problem, so that we need only to maximize $\left\{\log c_{t}+[\beta /(1-\beta)] \log \left(1-d+x_{t}\right)\right\}$ each period, subject to $a=c_{t}+x_{t}\left(1+\phi x_{t} / 2\right)$. This maximization leads to a fixed $c^{\mathbf{A}}$ and $x^{\mathbf{A}}$ (i.e., optimal $c$ and $x$ under autarky) for all $t$, with $x^{\mathbf{A}}$ given by the largest root of

$$
(1-\beta)(1+\phi x)(1-d+x)-\beta a+\beta x(1+\phi x / 2)=0
$$

$c^{\mathbf{A}}$ is then given as

$$
c^{\mathbf{A}}=a-x^{\mathbf{A}}\left[1-\phi x^{\mathbf{A}} / 2\right] .
$$

Note that since $c^{\mathrm{A}}$ and $x^{\mathrm{A}}$ are invariant to $K_{0}$, we have from (A1.2) that $V^{\mathrm{A}}\left(\lambda K_{0}\right)-V^{\mathrm{A}}\left(K_{0}\right)=\sum_{t=0}^{\infty} \beta^{t} \log \left(\lambda K_{0}\right)-\sum_{l=0}^{\infty} \beta^{t} \log K_{0}=\log \lambda /(1-\beta)$. Thus,

$$
V^{\mathrm{A}}\left(\lambda K_{0}\right)=V^{\mathrm{D}}\left(K_{0}\right)+\log \lambda /(1-\beta) .
$$

By substitution of (A1.4) into (A1.2), we find the explicit solution for $V^{\mathrm{A}}\left(K_{0}\right)$

$$
\begin{aligned}
V^{\mathrm{A}}\left(K_{0}\right)= & \sum_{t=0}^{\infty} \beta^{t}\left\{\operatorname { l o g } \left[a-x^{\mathrm{A}}\left(1+\phi x^{\mathrm{A}} / 2\right]+\log K_{0}\right.\right. \\
& \left.+[\beta /(1-\beta)] \log \left(1-d+x^{\mathrm{A}}\right)\right\} \\
= & \log \left[a-x^{\mathrm{A}}\left(1+\phi x^{\mathrm{A}} / 2\right)\right] /(1-\beta)+\beta \log \left(1-d+x^{\mathrm{A}}\right) /(1-\beta)^{2} \\
& +\log K_{0} /(1-\beta) .
\end{aligned}
$$

The solution for the default utility $V^{\mathrm{D}}\left(K_{0}\right)$ is the same as for $V^{\mathrm{A}}\left(K_{0}\right)$ except that $a(1-\lambda)$ replaces $a$ in the equation for the growth rate (A1.3). That is, $x^{D}$ is the largest root of the equation

$$
(1-\beta)(1+\phi x)(1-d+x)-\beta a(1-\lambda)+\beta x(1+\phi x / 2)=0 .
$$

Then, as in (A1.6), we may write

$$
\begin{aligned}
V^{\mathrm{D}}\left(K_{0}\right)= & \log \left[a(1-\lambda)-x^{\mathrm{D}}\left(1+\phi x^{\mathrm{D}} / 2\right)\right] /(1-\beta) \\
& +\beta \log \left(1-d+x^{\mathbf{D}}\right) /(1-\beta)^{2}+\log K_{0} /(1-\beta) .
\end{aligned}
$$

It is easy to show that $x^{\mathrm{D}}<x^{\mathrm{A}}$, and $V^{\mathrm{D}}\left(K_{0}\right)<V^{\mathrm{A}}\left(K_{0}\right)$. 


\section{Appendix 2: Optimal growth without repudiation}

The planner solves

$$
\max \sum_{t=0}^{\infty} \beta^{t} \log C_{t}
$$

subject to

$$
\sum_{t=0}^{\infty}(1+r)^{-t} C_{t}=N W_{0}
$$

where $N W_{0}$ is consumer wealth. The solution to (A2.1) is

$$
\begin{aligned}
& C_{t}=C_{0} \beta^{t}(1+r)^{t}, \\
& C_{0}=(1-\beta) N W_{0} .
\end{aligned}
$$

Productive wealth $W_{0}$ is maximized by solving

$$
\max W_{0}=\sum_{t=0}^{\infty}(1+r)^{-t}\left\{a K_{t}-I_{t}\left[1+(1 / 2) \phi\left(I_{t} / K_{t}\right)\right]\right\},
$$

subject to

$$
K_{t+1}=K_{t}(1-d)+I_{t}
$$

If one calls $q_{t}$ the Lagrange multiplier associated with (A2.6), one finds

$$
\begin{aligned}
& x_{t} \equiv I_{t} / K_{t}=\left(q_{t}-1\right) / \phi, \quad \text { and } \\
& q_{t-1}(1+r)=q_{t}(1-d)+a+\phi x_{t}^{2} / 2 .
\end{aligned}
$$

The optimal path is obtained by selecting the unique value value of $q_{0}$ which satisfies the transversality condition. Here, $q_{0}$ is such that all $q_{t}$ will stay constant, so that $x_{t}$ is also a constant, $x^{*}$, which solves

$$
(1 / 2) x^{2}-x(r+d)+(a-d-r) / \phi=0 .
$$

The solution, $x^{*}$, which we look for is the smaller root of (A2.9) (the other solution can be ruled out by the second-order conditions of the optimization problem). The solution is shown in eq. (8) in the text. We let $1+g^{*}$ $\equiv 1+x^{*}-d . K_{t}$ is now defined by

$$
K_{t}=K_{0}\left(1+g^{*}\right)^{t}
$$


The productive wealth of the country is now defined by

$$
W_{0}=\left[a-x^{*}\left(1+\phi x^{*} / 2\right)\right]\left[(1+r) /\left(r-g^{*}\right)\right] K_{0}
$$

Net wealth (subtracting foreign debt $D$ ) is defined by $N W_{t}$

$$
N W_{t}=W_{t}-(1+r) D_{t}
$$

At initial time, $D_{0}=0$, so that $N W_{0}$ and $W_{0}$ coincide.

The law of motion of the debt is given by

$$
D_{t+1}=(1+r) D_{t}+C_{t}-\left[a-x^{*}\left(1+\phi x^{*} / 2\right)\right] K_{t} .
$$

Since $C_{t}=(1-\beta) N W_{t}=(1-\beta)\left[W_{t}-(1+r) D_{t}\right]$, we have

$$
\begin{aligned}
D_{t+1}= & (1+r) D_{t}+(1-\beta)\left[a-x^{*}\left(1+\phi x^{*} / 2\right)\right]\left[(1+r) /\left(r-g^{*}\right)\right] K_{t} \\
& -(1-\beta)(1+r) D_{t}-\left[a-x^{*}\left(1+\phi x^{*} / 2\right)\right] K_{t} .
\end{aligned}
$$

Now, define $d_{t}=D_{t} / K_{t}$. Note that $D_{t+1} / K_{t}=d_{t+1}\left(K_{t+1} / K_{t}\right)=\left(1+g^{*}\right) d_{t+1}$. Then, by dividing both sides of (A2.13) by $K_{t}$ we can write

$$
\begin{aligned}
d_{t+1}= & {\left[\beta(1+r) /\left(1+g^{*}\right)\right] d_{t} } \\
& +[(1+g)-\beta(1+r)]\left[a-x^{*}\left(1+\phi x^{*} / 2\right)\right] /\left(r-g^{*}\right) K_{t} .
\end{aligned}
$$

We begin with $d_{0}=0$. The country becomes and remains a net debtor as long as $\beta(1+r)<\left(1+g^{*}\right)$. This condition, which we assume, is more likely to hold when: the world interest rate $r$ is low, the future is heavily discounted ( $\beta$ small), investment is highly productive ( $a$ large), and the adjustment costs in investment, $\phi$, are small.

By solving (A2.14), starting from $d_{0}=0$, we find

$$
d_{t}=\left\{1-\left[\beta(1+r) /\left(1+g^{*}\right)\right]^{t}\right\}\left[a-x^{*}\left(1+\phi x^{*} / 2\right)\right] /\left(r-g^{*}\right)
$$

Note that as $t \rightarrow \infty, d_{t}$ asymptotically approaches $\bar{d}=\left[a-x^{*}\left(1+\phi x^{*} / 2\right)\right] /$ $\left(r-g^{*}\right)$. When $d_{t}=d$, we have $(1+r)(D / W)=1$. Thus, consumption over GDP asymptotically approaches zero. 


\section{Appendix 3: Borrowing equilibrium with risk of debt repudiation}

Lenders' strategies

Consider the following optimization problem:

$$
V^{h}\left(K_{0}, D_{0}\right)=\max \sum_{t=0}^{\infty} \beta^{t} \log C_{t}
$$

such that

$D_{t+1}=D_{t}(1+r)+C_{t}+I_{t}\left[1+(\phi / 2)\left(I_{t} / K_{t}\right)\right]-a K_{t}$,

$K_{t+1}=K_{t}(1-d)+I_{t}$

$D_{t+1} \leqq h K_{t+1}$

with $D_{0} \leqq h K_{0}$ and $D_{0}, K_{0}$ given.

Define the following variables:

$$
c_{t} \equiv C_{t} / K_{t}, \quad d_{t} \equiv D_{t} / K_{t}, \quad x_{t} \equiv I_{t} / K_{t} .
$$

Then, the problem in (A3.1) can be rewritten as

$$
V^{h}\left(K_{0}, D_{0}\right)=\max \sum_{t=0}^{\infty} \beta^{t} \log c_{t}+\sum_{t=0}^{\infty} \beta^{t} \log K_{t},
$$

such that

$\left(1-d+x_{t}\right) d_{t+1}=(1+r) d_{t}+c_{t}+x_{t}\left[1+(\phi / 2) x_{t}\right]-a$,

$K_{t+1}=K_{t}\left(1-d+x_{t}\right)$

$d_{t+1} \leqq h$,

with $d_{0}, K_{0}$ given, and $d_{0} \leqq h$.

Using the same method as in Appendix 1, (A3.2) may be rewritten again as

$$
\begin{aligned}
V^{h}\left(K_{0}, D_{0}\right)= & \max \sum_{t=0}^{\infty} \beta^{t} \log c_{t}+\left(\log K_{0}\right) /(1-\beta) \\
& +\sum_{t=0}^{\infty}\left[\beta^{t+1} /(1-\beta)\right] \log \left(1+d+x_{t}\right),
\end{aligned}
$$

such that $\left(1-d+x_{t}\right) d_{t+1}=(1+r) d_{t}+c_{t}+x_{t}\left[1+(\phi / 2) x_{t}\right]-a$, and $d_{t+1} \leqq h$. 
Note that we no longer need the equation of motion for $K_{t}$, since $K_{t}$ is no longer part of the objective function.

The optimal policy for $c_{t}, x_{t}$ in (A3.3) is clearly independent of $K_{0}$, for a given $d_{0}\left(=D_{0} / K_{0}\right)$, since the objective function is additively separable in $K_{0}$, and the dynamic constraints do not depend on $K_{0}$. Thus, $V^{h}\left(\lambda K_{0}, \lambda D_{0}\right)-$ $\left(V^{h}\left(K_{0}, D_{0}\right)=\left(\log \lambda K_{0}\right) /(1-\beta)-\left(\log K_{0}\right) /(1-\beta)=\log \lambda /(1-\beta)\right.$.

Rearranging, we have

$$
V^{h}\left(\lambda K_{0}, \lambda D_{0}\right)=V^{h}\left(K_{0}, D_{0}\right)+\log \lambda /(1-\beta)
$$

as asserted in Lemma 1.

Now, choose $\lambda=1 / K_{0}$, so that we find $V^{h}\left(1, D_{0} / K_{0}\right)=V^{h}\left(K_{0}, D_{0}\right)-$ $\left.\left(\log K_{0}\right) / 1-\beta\right)$. Since we already know from Appendix 1 that $V^{\mathrm{D}}\left(K_{0}\right)=$ $V^{\mathrm{D}}(1)+\log \left(K_{0}\right) /(1-\beta)$, we see that

$$
V^{h}\left(K_{0}, D_{0}\right)(\gtreqless) V^{\mathrm{D}}\left(K_{0}\right) \text { if and only if } V^{h}\left(1, D_{0} / K_{0}\right)(\gtreqless) V^{\mathrm{D}}(1) \text {. }
$$

It is easy to show that $V$ is strictly decreasing in its second argument (more debt is strictly worse than less debt). Thus there is at most one value $\hat{h}=D_{0} / K_{0} \leqq h$ such that $V^{h}(1, \hat{h})=V^{\mathrm{D}}(1)$, and if such $\hat{h}$ exists, then

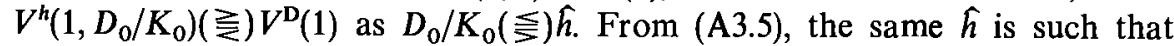
$V^{h}\left(K_{0}, D_{0}\right)(\gtreqless) V^{\mathrm{D}}\left(K_{0}\right)$ as $D_{0}(\lesssim) \hat{h} K_{0}$.

Now, suppose we find an $h^{*}$ such that $V^{h^{*}}\left(1, h^{*}\right)=V^{\mathrm{D}}(1)$. Then, $V^{h^{*}}\left(K_{0}, D_{0}\right)(\gtreqless) V^{\mathrm{D}}\left(K_{0}\right)$ as $D_{0}(\lesssim) h^{*} K_{0} . V^{h^{*}}, V^{\mathrm{D}}$, and $h^{*}$ then constitute an equilibrium of the capital market, as defined by (24) in the text with $V^{\mathbf{R}}=V^{h^{*}}$. We now derive the equilibrium $h^{*}$.

Let us first derive $V^{h^{*}}\left(1, h^{*}\right)$. This is the solution to

$$
\max \sum_{t=0}^{\infty} \beta^{t} \log c_{t}+\sum_{t=0}^{\infty}\left[\beta^{t+1} /(1-\beta)\right] \log \left(1-d+x_{t}\right),
$$

such that

$$
\begin{aligned}
& \left(1-d+x_{t}\right) \dot{d}_{t+1}=(1+r) d_{t}+c_{t}+x_{t}\left[1+\phi x_{t} / 2\right]-a, \\
& d_{t+1} \leqq h \text { and } d_{0}=h^{*} .
\end{aligned}
$$

We set up the Lagrangian for the problem as

$$
\begin{gathered}
\mathscr{L}=\sum_{t=0}^{\infty} \beta^{t}\left\{\log c_{t}+[\beta /(1-\beta)] \log \left(1-d+x_{t}\right)+\beta^{t} \lambda_{t}\left\{\left(1-d+x_{t}\right) d_{t+1}\right.\right. \\
\left.\left.-(1+r) d_{t}-c_{t}-x_{t}\left[1+\phi x_{t} / 2\right]+a\right\} \beta^{t} \mu_{t+1}\left[d_{t+1}-h\right]\right\} .
\end{gathered}
$$


(a) $1 / c_{t}=\lambda_{t}$ $\left(\partial \mathscr{L} / \partial c_{t}=0\right)$

$$
[\beta /(1-\beta)] /\left(1-d+x_{t}\right)+\lambda_{t} d_{t+1}-\lambda_{t}\left(1+\phi x_{t}\right)=0
$$$$
\left(\partial \mathscr{L} / \partial x_{t}=0\right)
$$
$\left(1-d+x_{t}\right) \lambda_{t-1} / \beta-\lambda_{t}(1+r) \mu_{t} / \beta=0$ $\left(\partial \mathscr{L} / \partial d_{t}=0\right)$.

To these first-order conditions we add the budget constraint from (A3.6)

$$
\left(1-d+x_{t}\right) d_{t+1}=(1+r) d_{t}+c_{t}+x_{t}\left[1+\phi x_{t} / 2\right]-a
$$

Solutions to (a) through (d) are given by constant values of $c, \lambda, x$, and $\mu$, with $d_{t}=h$ for all $t$. Using (a), (b), and (d) we find the optimal $x^{h}$ as the positive root to the following equation:

$$
\begin{aligned}
{[(2-\beta) \phi] x^{2} } & +2[(1-d)(1-\beta) \phi-(h-1)] x \\
& +2[-\beta a+\beta h(r+d)-(1-d)(1-\beta)(h-1)] .
\end{aligned}
$$

Now, we rewrite the budget constraint $d_{t+1}\left(1-d+x_{t}\right)=(1+r) d_{t}+c_{t}+$ $x_{t}\left[1+(\phi / 2) x_{t}\right]-a$ to give $c_{t}$ as a function of $x^{h}$. Since $d_{t}=d_{t+1}=h$, we have

$$
c^{h}=\left(x^{h}-r-d\right) h+a-x^{h}\left[1+\phi x^{h} / 2\right]
$$

Note that $c^{h}$ is written without a time subscript, now since consumption per unit capital is a constant along the optimal path. We now plug $c$ and $x^{h}$ back into the utility function in (A3.6) to get

$$
\begin{aligned}
V^{h}(1, h)= & \sum_{t=0}^{\infty} \log \beta^{t} c^{\bar{h}}+\sum_{t=0}^{\infty}\left[\beta^{t+1} /(1-\beta)\right] \log \left(1-d+x^{h}\right), \quad \text { or } \\
V^{h}(1, h)= & \log \left[\left(x^{h}-r-d\right) h+a-x^{h}\left(1+\phi x^{h} / 2\right)\right] /(1-\beta)+\left[\beta /(1-\beta)^{2}\right] \\
& \times \log \left(1-d+x^{h}\right) .
\end{aligned}
$$

The last equation is found by substituting (A3.10) into (A3.11). Note that $\mathrm{d}\left[V^{h}(1, h)\right] / \mathrm{d} h=\partial V^{h} / \partial h+\left(\partial V^{h} / \partial x^{h}\right) \partial x^{h} / \partial h=\partial V^{h} / \partial h$, where the last inequality follows from the envelope theorem (i.e., from the fact that with an optimal choice of $\left.x, \partial V^{h} / \partial x=0\right)$. Thus, $\operatorname{sign}\left(\mathrm{d} V^{h} / \mathrm{d} h\right)=\operatorname{sign}\left(x^{h}-r-d\right)<0$, so that $V^{h}(1, h)$ is strictly decreasing in $h$.

Now, it is easy to prove that there exists a unique $h^{*}$ such that $V^{h^{*}}\left(1, h^{*}\right)=$ $V^{\mathrm{D}}(1)$. First, $V^{0}(1,0)=V^{\mathrm{A}}(1)$, since $h=0$ implies no borrowing at all. But $V^{\mathrm{A}}(1)>V^{\mathrm{D}}(1)$, so that $V^{h}(1, h)>V^{\mathrm{D}}(1)$ for $h=0$. Now, consider $V^{\bar{d}}(1, \bar{d})$, where $\bar{d}$ is the limit of $D_{t} / K_{t}$ in the no-repudiation case of Appendix 1. Since $c$ equals zero in the limit in that case, $V^{\bar{d}}(1, \bar{d})=-\infty<V^{\mathrm{D}}(1)$. Thus, since $V^{0}(1,0)>V^{\mathrm{D}}(1)>V^{\bar{d}}(1, \bar{d})$, and since $V^{h}(1, h)$ is strictly decreasing in $h$, there must exist an $h^{*}$ between 0 and $d$, such that $V^{h^{*}}\left(1, h^{*}\right)=V^{\mathrm{D}}(1)$. In particular 
$h^{*}$ is the unique root of the equation

$$
\begin{gathered}
\log \left\{\left(x^{h}-r-d\right) h+a-x^{h}\left[1+(\phi / 2) x^{h}\right]\right\}+[\beta /(1-\beta)] \log \left(1-d+x^{h}\right) \\
=\log \left\{a(1-\lambda)-x^{\mathrm{D}}\left[1+(\phi / 2) x^{\mathrm{D}}\right]\right\}+[\beta /(1-\beta)] \log \left(1-d+x^{\mathrm{D}}\right)
\end{gathered}
$$

where $x^{h}$ is the positive root of (A3.8) and $x^{\mathrm{D}}$ is the positive root of (A1.7).

We can readily establish various properties of $h^{*}$. By total differentiation of (A3.12), we have

$$
\begin{aligned}
& \left.\mathrm{d} h^{*} / \mathrm{d} a=\left[\xi_{2}-\xi_{1}(1-\lambda)\right] / \xi_{2}\left(r+d-x^{h}\right)\right]>0, \\
& \mathrm{~d} h^{*} / \mathrm{d} \lambda=-a \xi_{1} /\left[\xi_{2}\left(x^{h}-r-d\right)\right]>0, \\
& \mathrm{~d} h^{*} / \mathrm{d} \beta=\log \left[\left(1-d+x^{h}\right) /\left(1-d+x^{d}\right)\right] /\left[(1-\beta)^{2} \xi_{2}\left(r+d-x^{h}\right)\right]>0, \\
& \mathrm{~d} h^{*} / \mathrm{d} r=h \xi_{2} /\left[\xi_{2}\left(x^{h}-r-d\right)\right]<0,
\end{aligned}
$$

where

$$
\begin{aligned}
& \xi_{1}=\left[a(1-\lambda)-x^{d}\left(1+\phi x^{d} / 2\right)\right]^{-1}>0, \\
& \xi_{2}=\left[\left(x^{h}-r-d\right) h+a-x^{h}\left(1+\phi x^{h} / 2\right)\right]^{-1}>0 .
\end{aligned}
$$

Finally, let us show that

$$
h<1+\phi x^{h}
$$

This inequality can be derived directly from eq. (A3.8). Another way is as follows. Eq. (A3.8) can be derived from

$$
\max _{x} V^{h}(1, h)
$$

(A3.15) says that $x^{h}$ maximizes the utility which is reached when the constraint on the debt is binding. The first-order condition [using the definition of $V^{h}$ in eq. (A3.11)] yields

$$
(1+\phi x-h)(1+x-d)(1-\beta)=\beta[h(x-r-d)+a-x(1+\phi x / 2)]
$$

The right-hand side is positive (it measures consumption per unit of capital). Therefore, $(1+\phi x-h)(1+x-d)(1-\beta)$ is positive, so that (A3.14) follows. (A3.16), when developed, yields (A3.8). 
Two-staged growth

Now that we have characterized the lending strategy by $D_{t} \leqq h^{*} K_{t}$, we can describe explicitly the optimal pattern of growth. From eq. (A3.7), we can write

$$
\begin{aligned}
\left(1+\phi x_{t-1}\right)(1+r)= & {\left[a+\phi x_{t}^{2} / 2+(1-d)\left(1+\phi x_{t}\right)\right]\left[1-\gamma_{t-1}\right] } \\
& +d_{t}(1+r) \gamma_{t-1}
\end{aligned}
$$

with $\gamma_{t-1}=\mu_{t} /\left[\lambda_{t-1}\left(1+x_{t-1}-d\right)\right]$, when the constraint $D_{t} \leqq h K_{t}$ is not binding, the shadow price $\gamma_{t-1}$ is zero, so that the dynamics of the system can simply be written

$$
\left(1+\phi x_{t-1}\right)(1+r)=\left[a+\phi x_{t}^{2} / 2+(1-d)\left(1+\phi x_{t}\right)\right]
$$

Let us call $T$ the time when the constraint on the debt is first binding (i.e., the first period for which $D_{t}=h K_{t}$ ). For $t \leqq T-2$, we have $\gamma_{t}=0$, while for $t \geqq T-1, \gamma_{t}>0$. After time $T$, the value of $x_{t}$ will be constantly held to $x_{h}$. All that we need in order to find the entire sequence $\left\{x_{t}\right\}$ is the value $x_{T-1}$ and to define the sequence $\left\{x_{t}\right\}_{t \leq T-2}$ by backward application to eq. (A3.18).

At time $T-1$, eq. (A3.17) can be written

$$
\begin{aligned}
\left(1+\phi x_{T-1}\right)(1+r)= & {\left[a+\phi x_{h}^{2} / 2+\left(1+\phi x_{h}\right)(1-d)\right]\left[1-\gamma_{T-1}\right] } \\
& +h \gamma_{T-1}(1+r)
\end{aligned}
$$

(Note that we have substituted $x_{h}=x_{T}$.) In order to find the equilibrium value of $x_{T-1}$ and $\gamma_{T-1}$, we need only to consider one more equation in $x_{T-1}$ and $\gamma_{T-1}$. From the system (A3.7), we can derive

$$
\begin{gathered}
{\left[c_{h}\left(1-\gamma_{T-1}\right)\right] /[\beta(1+r)]=h-\left[(1+r) d_{T-1}+x_{T-1}\left(1+\phi x_{T-1}\right)-a\right] /} \\
\\
{\left[1+x_{t-1}-d\right] .}
\end{gathered}
$$

Eq. (A3.20) can be shown to be an upward sloping line for the values of $x_{T-1}$ which are above $x^{h}$. When $d_{t-1}=h$, eq. (A3.20) is a modified version of the current account equation when the constraint on the debt is binding: the line would pass through $\left(x^{h}, \gamma_{h}\right)$, with $\gamma_{h}$ the stationary state value of $\gamma_{t}$ when the constraint is binding. One can also check that a lower value of $d_{t-1}$ yields a higher value of $x_{t-1}$.

The system (A3.19), (A3.20) defines the equilibrium value of $\left(x_{T-1}, \gamma_{T-1}\right)$. Here, we shall prove that (A3.19) defines a downward sloping line. To see 
this, one need only to check that

$$
h(1+r)<(1-d)\left(1+\phi x^{h}\right)+a+\phi x_{h}^{2} .
$$

We already know that

$$
h<1+\phi x^{h}
$$

so that we only need check that

$$
(1+r)\left(1+\phi x^{h}\right)<(1-d)\left(1+\phi x^{h}\right)+a+\phi x_{h}^{2} / 2
$$

or, equivalently, that

$$
\phi x_{h}^{2} / 2-(r+d) \phi x^{h}+a-r-d \geqq 0 .
$$

To see this, it is enough to write eq. (A3.17) when $t=T+1$. Both values $x_{T}$ and $x_{T+1}$ are equal to the stationary state value $x^{h}$. Since $h<1+\phi x^{h}$, eq. (A3.17) can be rewritten to yield the inequality in (A3.23).

We can now represent eq. (A3.19) as a downward sloping line. Its intersection with the upward sloping line defines the equilibrium value of $\left(x_{T-1}, \gamma_{T-1}\right)$. Since the upward sloping line is below $H_{h}$ (defined by $d_{t-1}=h$ ), this shows that $x_{T-1}$ is greater than $x^{h}$.

We can now see the full dynamics of the system. First, note that eq. (A3.18) shows that $x^{h}$ is lower than $x^{*}$, the optimal rate of capital accumulation. Second, note that $x_{T-1}$ is below $x^{*}$ [from eq. (A3.19)], and eq. (A3.21): $\left(1+\phi x_{T-1}\right)(1+r)<a+\phi x_{h}^{2} / 2+\left(1+\phi x^{h}\right)(1-d)<a+\phi x^{* 2} / 2+\left(1+\phi x^{*}\right)$ $(1-h)=\left(1+\phi x^{*}\right)(1+r)$, so that $x_{T-1}<x^{*} . x_{T-1}$ takes therefore some intermediate value between $x^{h}$ and $x^{*}$ and the dynamics are clear.

\section{Appendix 4: Proof of Proposition 3}

Let us prove that $\Omega$ coincides with $V$ in 5 steps.

Step 1. First, we show

$$
\Omega\left(\lambda D_{0}, \lambda K_{0}\right)=\Omega\left(D_{0}, K_{0}\right)+\log \lambda /(1-\beta) .
$$

The argument is as in Appendix 3. If $\left\{C_{t}, I_{t}\right\}$ is an optimal solution to $\Omega\left(D_{0}, K_{0}\right),\left\{\lambda C_{t}, \lambda I_{t}\right\}$ is an optimal solution to $\Omega\left(\lambda D_{0}, \lambda K_{0}\right)$.

Step 2. In the constraint (34), we can write $\Omega\left(D_{s}, K_{s}\right)$ in place of $\sum_{t=s}^{\infty} \beta^{(t-s)} \log C_{t}$. The proof uses a standard argument of dynamic program- 
ming. If the right-hand side did not coincide with $\Omega$ (which is the maximum one can reach at time $s)$, then one could increase $\Omega\left(D_{0}, K_{0}\right)$ by changing $\left\{C_{t}, I_{t}\right\}_{t \geqq s}$, to the solution $\left\{C_{t}^{\prime}, I_{t}^{\prime}\right\}_{t \leq s}$, which maximizes $\Omega\left(D_{s}, K_{s}\right)$. Clearly this change would not violate inequality (34). Thus, (33) can be rewritten as

$$
\Omega\left\{D_{0}, K_{0}\right]=\max _{\left\{C_{t}, I_{t}, D_{t}\right\} t=0} \sum_{t=0}^{\infty} \beta^{t} \log C_{t}
$$

subject to $\Omega\left[D_{s}, K_{s}\right] \geqq V^{\mathrm{D}}\left(K_{s}\right)$, and (2), (4), (13), (16) and (30).

Step 3. There exists an $h_{\Omega}$ such that $\Omega\left(D_{0}, K_{0}\right) \geqq V^{\mathrm{D}}\left(K_{0}\right) \Leftrightarrow D \leqq h_{\Omega} K_{0}$. The argument is as in Appendix 3 when (A4.1) is acknowledged.

Step 4. From Steps 2 and $3, \Omega\left(D_{0}, K_{0}\right)$ can be written $\Omega\left(D_{0}, K_{0}\right)$ $=\max \sum_{t=0}^{\infty} \beta^{t} \log C_{t}$ subject to $D \leqq h_{\Omega} H$.

Step 5.

$$
h_{\Omega}=h^{*}
$$

$h_{\Omega} \geqq h^{*}$, since $\Omega$ defines the optimum optimorum. But $h^{*} \geqq h_{\Omega}$, since $h^{*}$ defines the largest $D / K$ retio which keeps the country from defaulting.

\section{References}

Bardhan, Pranab, 1967. Optimum foreign borrowing, in: Karl Shell, ed., Essays on the theory of optimal economic growth (MIT Press, Cambridge, MA).

Borchard, Edwin, 1951, State insolvency and foreign bondholders, vol. 1, General principles (Yale University Press, New Haven, CT).

Bulow, Jeremy I. and John B. Shoven, 1978, The bankruptcy decision, Bell Journal of Economics, 437-456.

Cohen, Daniel and Jeffrey Sachs, 1984, LDC borrowing with default risk, Kredit und Kapital, special issue on international banking.

Cohen, Daniel and Jeffrey Sachs, 1985, The debt of nations (Harvard University, Cambridge, MA) forthcoming.

D'Autume, A. and P. Michel, 1983, Epargue et investissement et monnaie dans une perspective intertemporelle (INSEE, Paris).

Eaton, Jonathan and Mark Gersovitz, 1981a, Poor country borrowing in private financial markets and the repudiation issue (International Finance Section, Princeton, NJ).

Eaton, Jonathan and Mark Gersovitz, 1981b, Debt with potential repudiation: Theoretical and empirical analysis, Review of Economic Studies 48.

Eaton, Jonathan and Mark Gersovitz, 1981c, Country risk: Economic aspects (Yale University, New Haven, CT) unpublished manuscript.

Feis, Herbert, 1930, Europe: The World's Banker, 1870-1914 (Yale University Press, New Haven, CT).

Foley, Duncan K. and Martin Hellwig, 1975, A note on the budget constraint in a model of borrowing, Journal of Economic Theory 11, 305-314.

Grossman, Sanford J. and Oliver D. Hart, 1980, Corporate financial structure and managerial incentives, Conference paper no. 48 , May. 
Guitian, Manuel, 1981, Policies on access to fund resources - An overview of conditionality (International Monetary Fund, Washington, DC) manuscript.

International Monetary Fund, 1980, International capital markets, Occasional paper no. 1, Sept. (IMF, Washington, DC).

International Monetary Fund, 1981, External indebtedness of developing countries, Occasional paper no. 3, May (IMF, Washington, DC).

Jensen, Michael and William Meckling, 1976, Theory of the firm: Managerial behavior, agency costs, and capital structure, Journal of Financial Economics 3, 305-360.

Madden, John T., Marcus Nadler and Harry C. Sauvain, 1937, America's experience as a creditor nation (Prentice-Hall, New York).

Myers, Stewart C., 1977, Determinants of corporate borrowing, Journal of Finance 5, 147-155.

Sachs, Jeffrey D., 1981, The current account and macroeconomic adjustment in the 1970s, Brookings Papers on Economic Activity 2.

Sachs, Jeffrey D., 1982a, The current account in the macroeconomic adjustment process, Scandinavian Journal of Economics 84 (2).

Sachs, Jeffrey D., 1982b, Aspects of the current account behavior of OECD economics, NBER Working paper no. 859, Feb. (NBER, Cambridge, MA).

Sachs, Jeffrey D., 1982c, Problems and prospects, in: P. Wachtel, ed., Crises in the economic and financial structure Lexington, MA).

Sachs, Jeffrey D., 1984, Theoretical issues in international borrowing, Princeton Studies in International Finance, no. 54.

Smith, Clifford and J. Warner, 1979, On financial contracting: An analysis of bond covenants, Journal of Financial Economics 7, 117-161.

Stiglitz, J. and A. Weiss, 1981, Credit rationing in markets with imperfect information: I, American Economic Review.

Winkler, Max, 1933, Foreign bonds: An autopsy (Swain, Philadelphia, PA).

Wynne, William H., 1951, State insolvency and foreign bondholders, vol. 11, Case histories (Yale University Press, New Haven, CT). 


\title{
COMMENT
}

\section{'A Geometrical Analysis of the Incentives for Default and Credit Rationing' by Daniel Cohen and Jeffrey Sachs}

\author{
William D. NORDHAUS
}

Yale University, New Haven, CT06520, USA

The paper by Cohen and Sachs forms part of a growing literature attempting to understand and explain the enormously complex set of phenomena surrounding the international debt issue. Its strength is that it places the discussion of lenders and sovereign borrowers into an explicit intertemporal framework and derives therein an explicit description of debt dynamics. Its weakness is mainly that, as a purely theoretical exercise, we are left unsure about whether it describes wordly phenomena or whether, like a growing part of economic literature, it is self-referential. In my comments I will undertake both to explain the Cohen-Sachs results and to place them in the context of behavior in the trenches of economic life.

Fig. 1 describes the apparatus concisely in a static framework. A country contracts debt $D$. With this debt it is able to produce gross wealth (equal to the present value of income) shown as $W(D)$. With no debt, the country is at autarky point, $N$. But, at least in the more realistic model of part 4 , the marginal product of debt (equal to the marginal product of capital times the

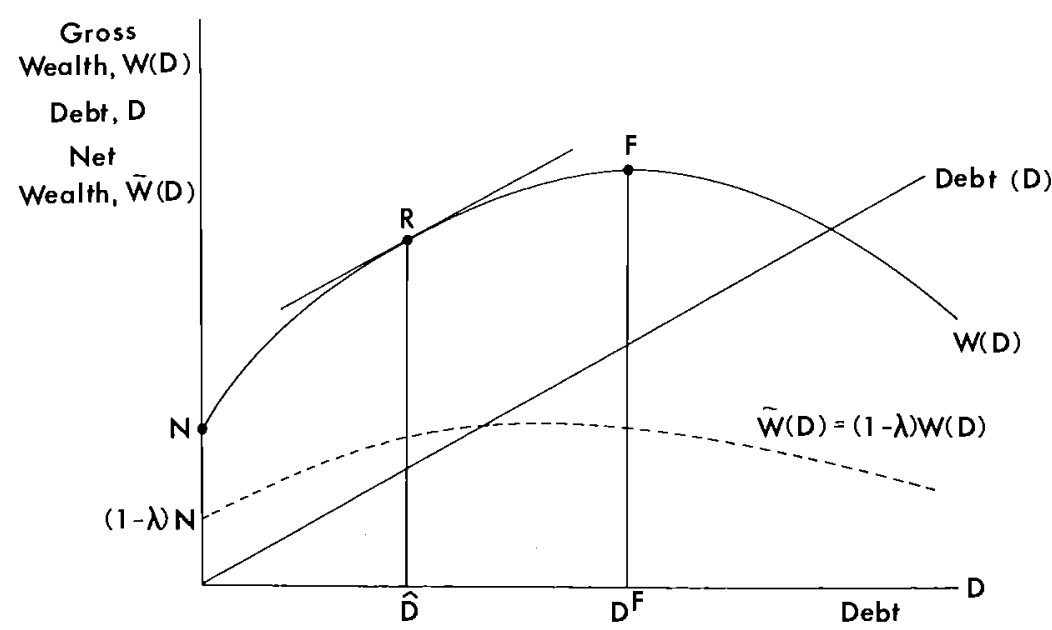

Fig. 1. Wealth and net wealth without default. 
fraction of debt going into capital) is higher than the interest rate on the debt - hence the $W(D)$ curve rises rapidly at first. Then the country gradually becomes saturated with capital and debt, so $W^{\prime}(D)=0$ at $D^{\mathrm{F}}$. A country wishes to maximize its net wealth (or discounted value of income after either paying off debt or defaulting). If a country undertakes to repay its debt, then its wealth is equal to gross wealth less debt, shown as the solid line in fig. 2.

To understand a country's incentive to repay its debt, we consider curves showing the effect of repudiation. In fig. 1, repudiation lowers net wealth to $\tilde{W}(D)=(1-\lambda) W(D)$, shown as the dashed line. According to Cohen-Sachs, the $\tilde{W}(D)$ line lies exactly $(1-\lambda)$ below the $W(D)$ line, reflecting the assumption that the fraction $\lambda$ of output, and hence of the present value of output, is lost because of loss of access to capital markets as well as because of other forms of economic retaliation.

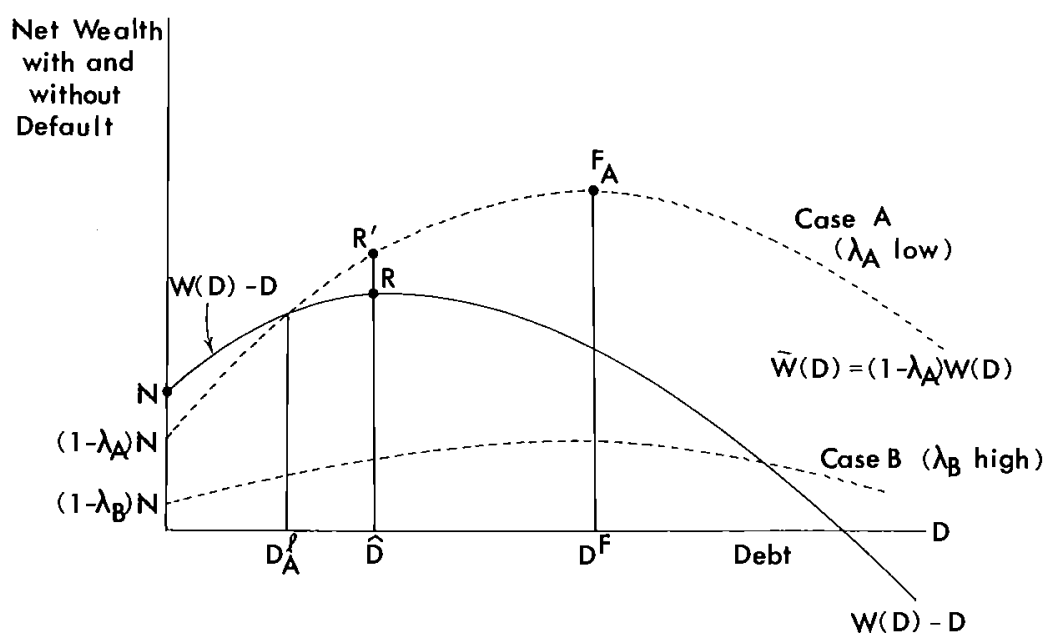

Fig. 2. Net wealth with and without default; lending limits at $D_{\mathrm{A}}^{l}$.

Fig. 2 lays out a country's choices. If a country plays the repayment game, it stays on the solid line; as long as it knows it will always play the repayment game, its best policy is to borrow only up to point $\hat{D}$, the honest optimum.

If a country is contemplating repudiation, it must consider dashed lines in fig. 2, which represent net wealth after repudiation. If $\lambda$ is high (as in case B of fig. 2), then it will never pay for a country to repudiate its debts. Lenders know that repudiation doesn't pay, so they need not constrain lending. Cohen and Sachs' Proposition 1 concerns the corner solution of $\lambda=1$, but there must also be a whole range of relatively high $\lambda$ 's where repudiation does not pay so banks need not restrain lending. 
The more interesting situation in case $A$, where losses from repudiation are low. Note that for any debt level greater than $D_{A}^{l}$, a country is better off repudiating its debt than repaying its debt. At the honest optimal debt level $\widehat{D}$, a country's wealth rises from $\mathbf{R}$ to $\mathbf{R}^{\prime}$ 'after repudiation.

Enter the lenders. As Cohen and Sachs show, because lenders understand borrowers' options, they will never lend more than $D_{\mathrm{A}}^{l}$ in fig. 2 . For debt levels up to $D_{\mathrm{A}}^{l}$, lenders prefer not to default. Cohen and Sachs show that until debt is accumulated up to $D_{\mathrm{A}}^{l}$, there will be no credit rationing. But once borrowers reach $D_{\mathrm{A}}^{l}$, lenders will lend no more for fear of leading borrowers into temptation.

Using this informal graphical apparatus, we can perhpas shed some light on realistic aspects of international indebtedness.

(I) To begin with, it is apparent that there is a threshold $\lambda^{*}$, which is given by $\left(1-\lambda^{*}\right) W\left(D^{\mathrm{F}}\right)=W(\hat{D})-\hat{D}$. For $\lambda$ is greater than $\lambda^{*}$, credit rationing is necessary. For $\lambda$ less than $\lambda^{*}$, the painful consequences of default make credit rationing unnecessary.

(2) This insight leads to a second and paradoxical conclusion. If we can make the consequences of default sufficiently automatic and painful, then borrowers will exercise the necessary restraint on themselves. Conversely, the more humane and generous become the institutions of national bankruptcy and IMF lending, the more will lenders have to protect their portfolios. Hence, it is in the interest of debtors to make the rules of default more draconian. By raising the cost of default, default becomes less attractive and lenders will thereby raise their lending limits. (I might add that $I$ have yet to find a constrained country that espoused draconian consequences of default or debt rescheduling - just as I have yet to find a lender who advocated repeal of usury legislation or a homeless person lobbying for decontrol of apartment rents. The inability of people to perceive subtle self-interests is troubling here as in other places.)

(3) A third point about the approach concerns the nature of the equilibrium. They propose that banks simply calculate the indifference point at $D^{l}$ in fig. 2 and then ration their lending. Alas, this would be a very poor policy because behavior at that point - and the payoffs - is violently asymmetrical. Start out in an equilibrium where a country - call it Mañanaland - has borrowed up to the limit, $D^{l}<\hat{D}$. Everyone is solvent; everyone is happy. Then a foolish go-go bank - Penn Square, if you will - lends a bit more, so Mañanaland decides to default. Mañanaland doesn't much care whether it defaults or not, but banks care a lot as they lose their entire portfolio of $D^{l}$-plus.

Or do they? Won't everyone be better off is the banks 're-schedule' the debt, effectively reducing Mañanaland's debt below the default threshold? Such a solution makes everyone better off - everyone except future lenders. But if lenders blink in the face of disaster (as they have every time to date), 
doesn't this give borrowers tremendous power to threaten default? Won't the whole process break down because default is so wasteful? If default never occurs, because default is never the solution of the relevant game, then the analysis becomes curiously irrelevant?

(4) Although the authors do not relate their paper to recent events, they might use their results to explain the dramatic decline in lending during the early 1980's. According to their theory, what occurred was that major Latin American countries were suddenly at the point where a default was economically attractive relative to repayment. Banks were reining in countries to keep them in the corral of responsible financial behavior.

While this explanation is ingenious, it is flying against a very powerful fact - that no non-communist country has defaulted since World War II. If all the big Latin American countries were really near the threshold, then one would certainly have tipped over the threshold and declared default after 1980. My hunch is that default is so undesirable that countries will go to any lengths to avoid it. If this hunch is correct, then countries are in case B of fig. 2 - they are not tempted to default and in fact are not being credit rationed to avoid default.

Surely, you will say, something was happening to debtor countries and to banks. What was happening was that countries were forcing banks to reschedule at the same time countries were being visited by the IMF. Perhaps this is the set of events to which the Cohen-Sachs paper applies. If a debt rescheduling is a partial default under another name, then banks will ration credit to Mañanaland as long as rescheduling is not unpleasant enough to make countries restrain themselves. So perhaps the Cohen-Sachs model really will apply to events of the 1980 's, where the analyzed event is the complex set of events involving IMF negotiations and debt rescheduling.

The curious factor here, however, is that the events surrounding an IMF visit are not well described by a high $\lambda$. Indeed, most orthodox economists would say that an IMF visit allows a country to undertake policies that improve future prospects, or have a negative $\lambda !$ By the Cohen-Sachs logic, won't every country desire rescheduling? Perhaps not. For an IMF visit is an interesting arrangement - somewhat like making convicted felons pick up garbage - which is immediately unpleasant to decisionmakers even though it is ultimately healthy to the country. It has a high psychic $\lambda$ and a negative real $\lambda$. Surely as an institution such an arrangement is far improved over the horribly inefficient mechanism of default - indeed from the point of view of institutional arrangements to combat self-selection and moral hazard, the arrangement is remarkable. 